OPEN ACCESS

Edited by:

Zoran Jovanović,

University of Belgrade, Serbia

Reviewed by:

Lei Wang,

Harbin Institute of Technology, China

Xiaoxia Le,

Ningbo Institute of Materials

Technology and Engineering, CAS,

China

*Correspondence:

Zhenlin Jiang

jiangzhenlin@sues.edu.cn

Fanfan Fu

fanfan.fu@ntu.edu.sg

Specialty section:

This article was submitted to Nanoscience,

a section of the journal

Frontiers in Chemistry

Received: 07 January 2021

Accepted: 14 May 2021

Published: 31 May 2021

Citation:

Zheng $Q$, Xu C, Jiang Z, Zhu M, Chen $C$ and Fu $F$ (2021) Smart

Actuators Based on External

Stimulus Response.

Front. Chem. 9:650358.

doi: 10.3389/fchem.2021.650358

\section{Smart Actuators Based on External Stimulus Response}

\author{
Qinchao Zheng ${ }^{1}$, Chenxue $\mathrm{Xu}^{1}$, Zhenlin Jiang ${ }^{1,2 *}, \mathrm{Min} \mathrm{Zhu}^{1}$, Chen Chen ${ }^{1}$ and Fanfan $\mathrm{Fu}^{3 *}$ \\ ${ }^{1}$ College of Chemistry and Chemical Engineering, Research Center for Advanced Mirco- and Nano-Fabrication Materials, \\ Shanghai University of Engineering Science, Shanghai, China, ${ }^{2}$ Science and Technology on Advanced Ceramic Fibers and \\ Composites Laboratory, National University of Defense Technology, Changsha, China, ${ }^{3}$ School of Materials Science and \\ Engineering, Nanyang Technological University, Singapore, Singapore
}

Smart actuators refer to integrated devices that are composed of smart and artificial materials, and can provide actuation and dampening capabilities in response to single/ multi external stimuli (such as light, heat, magnetism, electricity, humidity, and chemical reactions). Due to their capability of dynamically sensing and interaction with complex surroundings, smart actuators have attracted increasing attention in different application fields, such as artificial muscles, smart textiles, smart sensors, and soft robots. Among these intelligent material, functional hydrogels with fiber structure are of great value in the manufacture of smart actuators. In this review, we summarized the recent advances in stimuli-responsive actuators based on functional materials. We emphasized the important role of functional nano-material-based additives in the preparation of the stimulus response materials, then analyzed the driving response medium, the preparation method, and the performance of different stimuli responses in detail. In addition, some challenges and future prospects of smart actuators are reported.

Keywords: smart actuators, single stimuli, multi stimuli, drive response, functional nanomaterials

\section{INTRODUCTION}

With revolutionary developments of nanomaterials and bionics, smart actuators in response to natural muscles has attracted considerable attention in the last decade. Taking advantage of those functional materials with controllable shape or volume changes under external stimuli (such as light, heat, electricity, magnetism, humidity, and chemistry), smart actuators can convert such stimuli into mechanical energy in response to environmental stimuli ( $\mathrm{Xu}$ et al., 2015; Song et al., 2016; Shin et al., 2018; Li J. et al., 2019; Chortos et al., 2019; Sturm et al., 2019). Smart actuators have a wide range of application prospects in the fields of biomedicine, bionic robots, and smart medicine micro/nanomanipulators (Zang et al., 2013; Yao et al., 2015; Santhiago et al., 2016; Hua et al., 2018; Power et al., 2018; Jia H. et al., 2019). They are derived from smart materials with sensing and executive functions, as first proposed by

\footnotetext{
Abbreviations: AA: Acrylic acid; CNT: Carbon nanotube; DOPAC: 3,4-dihydroxyphenylacetic acid; GO: Graphene oxide; LDAM: Light-driven artificial muscle; Nano-G: Nanoscale graphite; NIR: Near-infrared; NP: Nanoparticle; PAA: Polyacrylic acid; PDA: Polydopamine; PDMS: Poly(dimethyl siloxane); PI: Polyimide; PNIPAm: Poly(N-isopropylacrylamide); P(NIPAmABP): Polymer poly(N-isopropylacrylamide)-acryloylbenzophenone copolymer; PU: Polyurethane; PVDF: Polyvinylidene difluoride; QCH: Quaternary ammonium chitosan; RGO: Reduced graphene oxide; SMA: Octadecyl ester; SRGO: Sericinfunctionalized reduced graphene oxide; TPE-4Py: Tetrakis (4-pyridinephenyl) ethylene; TPU: Thermoplastic polyurethane; GP graphite/polyaniline; PEGDGE: poly(ethylene glycol) diglycidyl ether.
} 


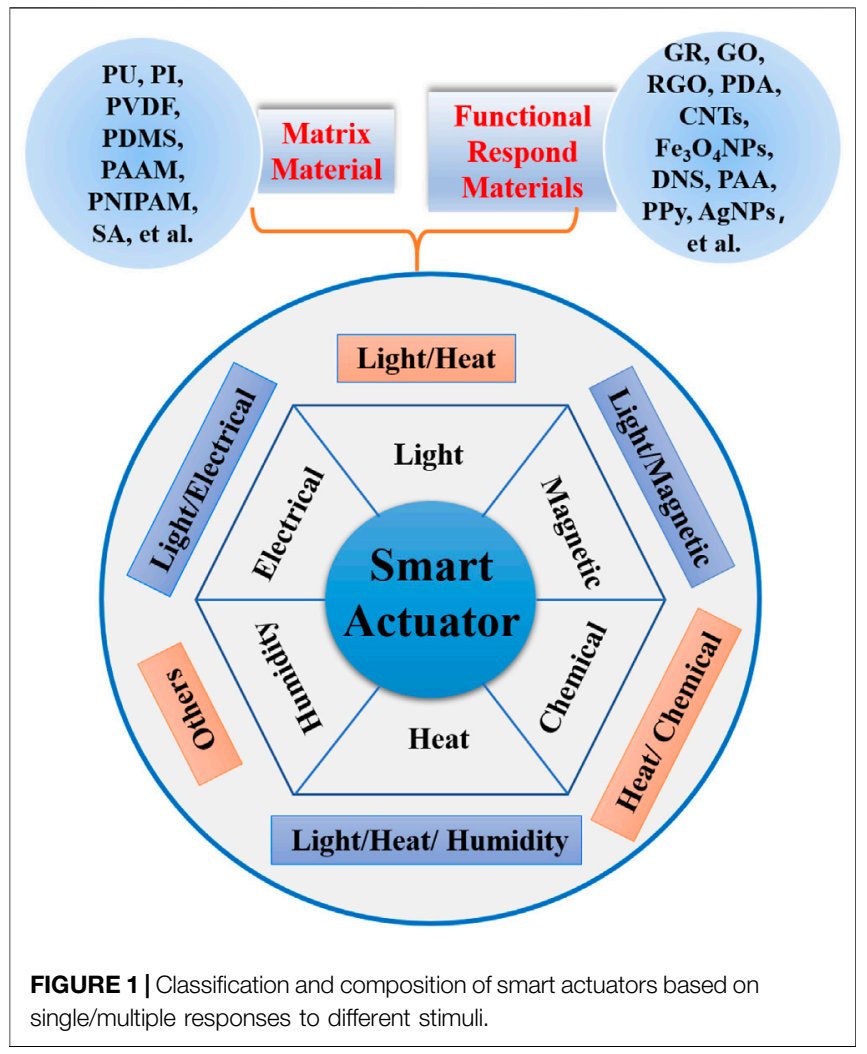

Toshiyoshi and Newham in the late 1980s. Subsequently, Finkelmann (Finkelmann et al., 2001) and Li (Li et al., 2003) used azobenzene-containing polymer liquid crystal hydrogels to prepare smart responsive materials that can bend under light stimulation. Yu et al. prepared liquid crystal polymer smart materials that can achieve controlled directional photochemical bending memory changes under ultraviolet (UV) irradiation (Yu et al., 2003).

Since the structure of nanomaterials consists of crystalline units and interfacial units, their quantum size effect and surface effect make them far superior to ordinary materials in terms of physicochemical properties (Hasan, 2020), including melting point, magnetic properties, optical properties, capacitive properties, and water solubility. So, smart actuators have evolved from initial light stimulus response to an exciter driven by single or multiple responses under different stimuli due to combine with functional nanomaterials. However, the classification boundaries of the actuator are still unclear. From the perspective of morphological structure, they can be classified into fiber (1D), membrane (2D), and block (3D) classes. In terms of stimulus responsiveness, they can be divided into single stimulus and multiple stimuli. This review discusses recent advances in smart actuators with different single stimulus and multiple stimuli response. We mainly focus on the recent progress of single and multiple responses smart actuators in points of material designs, fabrication methods, and performance (Figure 1). Finally, we discuss the current applications and possible new fields of interest for these smart actuators.

\section{SINGLE STIMULUS RESPONSE SMART ACTUATORS}

For smart actuators, the most critical attributes (Huang et al., 2012) that should be simultaneously performed are perception, processing, and response capabilities. Internal molecules perform the corresponding motion processing by sensing the external stimuli and causing the material drive and response, such as heat shrinkage and cold bending (Leng et al., 2011). For single stimulus response smart actuators, a better targeted response and timely shape change can be accomplished if there is only a single variation in the environment. In addition, actuators responsive to a single stimulus have a high response accuracy and stable response to remote control in actual applications that have more advanced preparation technologies.

\section{Smart Actuators Based on Light Stimulation Response}

Light stimulation is one of the most basic and direct methods for smart actuators, especially in single stimulus response research, owing to its several advantages, such as fast stimulus response, high rate of change in drive performance, and good stability. Photochromic molecules play a major role in light-responsive actuators, capturing light signals and translating these to useful property changes, thereby achieving changes in geometric size or shape and structure, and showing macroscopic motion characteristics (Jiang et al., 2006). This is similar to lightdriven mechanisms in nature.

Based on the characteristics of a fiber structure mimicking human muscles, CNTs were mixed with PU solution to form electrospinning precursor, and the so-made yarns can be triggered by NIR (Meng et al., 2019). Due to the high heat absorption property of CNTs, CNTs can enable the yarns to efficiently absorb NIR and radiate heat, which induces the fast temperature change that leads to the contraction/expansion motions along the axial direction. So, the yarns relaxed immediately, showing fast thermal radiation speed and the maximum contractive actuation of $6.7 \%$ after $6 \mathrm{~s}$ exposed to the NIR light, and returned to its initial state at $16 \mathrm{~s}$. Although the radiation speed is fast, the deformation efficiency is smaller, and it is also a common problem of fiber-based smart actuators. Different from fiber-based smart actuators, the common poor ductility of hydrogel smart actuators has been hindering the further application of light responsive actuators (Yu and Ikeda, 2010), NIR light responsive PNIPAM/GO composite hydrogels with ultra-high tension were prepared by combining different polymerization methods with UV polymerization (Shi et al., 2015) and 3D printing technology (Zhang et al., 2019). Combination of the GO and thermoresponsive PNIPAM polymeric networks provides the hydrogels with an excellent NIR light-responsive property, and the physical cross-linking of the GO increases the toughness of the nanocomposite hydrogel networks. Turning on or off the NIR light respectively caused the contraction and swelling of the actuator, which shows in Figure 2A. Furthermore, the fast and reversible NIR response characteristics of the actuator were realized by changing the GO 
A

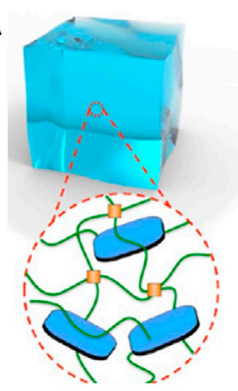

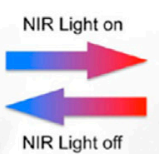

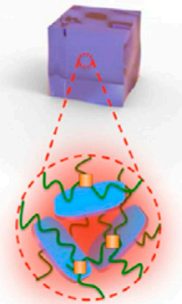

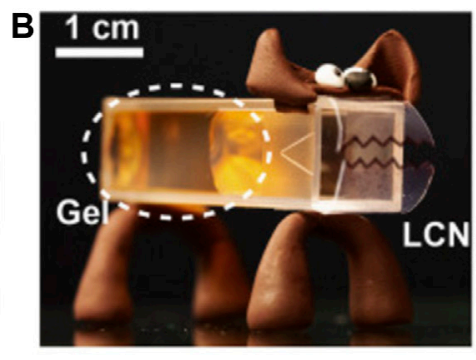

FIGURE 2 | (A) Reversible contraction of PNIPAM/GO nanocomposite hydrogels actuator responds to IR light stimulation. Reproduced from Shi et al. (2015) with permission of American Chemical Society. (B) Side view of the original dog after incubation at $50^{\circ} \mathrm{C}$ for 27 min, showing salivation (gel dripping). Reproduced from Zeng et al. (2020) with permission of Elsevier.

content and irradiation time of NIR light. In contrast, Kim et al. prepared light-responsive bilayer hydrogel actuators by crosslinking PNIPAM/ RGO composite hydrogels as the active layer and poly(acrylamide) hydrogels as the passivation layer. The volume of the active layer decreased through light simulation, while the passivated layer maintained its original size, and the asymmetric volume size induced the full bending motion of the bilayer actuator (Kim et al., 2016). Similarly, a bilayer composed of RGO and elastin-like polypeptides can be driven by an NIR laser, achieving $60^{\circ}$ bending in $1 \mathrm{~s}$, and recovering $84 \%$ in $10 \mathrm{~s}$ (Wang et al., 2013). Based on the application characteristics of liquid crystal networks in remote and wireless control of the bending of actuators, the photopolymerization of monoacrylate, diacrylate mesogens, and azobenzene chromophores were used to form light responsive switch molecules, and a non-binding multifunctional light-driven soft robot was also prepared from the different relaxed states of the curled shapes and light sensitivity (Pilz da Cunha et al., 2020). Heat was released through the isomerization process under light stimulation, thereby driving displacement of $20 \mathrm{~mm}$, and exhibiting a transportation behavior. In a recent example reported that autonomous walking and "salivation" behavior can also be achieved in artificial dogs under periodic light stimulation (Zeng et al., 2020), as shown in Figure 2B. In short, lightresponsive smart actuators are compelling because they can be remotely and accurately controlled, rapidly modulated, and easily focused on microscale drive field.

\section{Smart Actuators Based on Electrical Stimulation Response}

There are many types of materials with flexible or soft materials that can convert electrical energy into mechanical energy, including some polymers, gels, and even CNTs. Smart actuators driven by electrical signals can easily adjust its motion amplitude. Among the electrical stimulation responsive actuators, electroactive polymers are one of the most widely studied materials, which can change size or deform under electrical stimulation. Furthermore, this electroactive polymer can not only exhibit considerable strain and stress, strong mechanical flexibility, but also can provide the largest drive change in volume (Zhao et al., 2016). So, some of the biggest research breakthroughs are reported in artificial muscles (Takemura et al., 2008) and soft robots (Must et al., 2015; Nhat and Truong Thinh, 2015).

Xiao et al. reported a electromechanical bimorph actuator constituted by a GR layer and a PVDF layer (Xiao et al., 2016), and taking advantage of the differences in coefficient of thermal expansion between the two layers and the converse piezoelectric effect and electro strictive property of the PVDF layer, the fishlike robots could swim at a speed of $5.02 \mathrm{~mm} / \mathrm{s}$ applied the voltage of $0-13 \mathrm{~V}$ and the frequency of $0.4 \mathrm{~Hz}$, as shown in Figure 3A. Morales et al. combined two oppositely deforming polyelectrolyte hydrogels to create a walker (Morales et al., 2014). Under an electric field of $5 \mathrm{~V} / \mathrm{cm}$ constantly changing between positive and negative electrodes, the hydrogel chain moved across the cation/ anion gel interface to the oppositely charged electrode. With this, the adhesion of the polyion complex became stronger, thereby promoting the separation by reversing the electric field and resulting in a walking motion (Figure 3B). Electrical stimulus actuators generally have low energy conversion efficiency owing to the lack of active units in their microstructure. Lu et al. achieved a $6.03 \%$ energy conversion rate and strain capacity of $16.45 \%$, which are significantly higher than that of other CNTs with a graphene actuator voltage of $2.5 \mathrm{~V}$ (Lu C. et al., 2018). Electrical stimulus responsive actuators have a wide frequency spindle that allows it to bend at $0.1-30 \mathrm{~Hz}$. Recently, the coiled GO/CNTs yarns made by the biscrolling method can produce 19\% maximum tensile actuation (Hyeon et al., 2019), and compared with an original CNT artificial muscle with a work capacity of $2.6 \mathrm{~J} / \mathrm{g}, \mathrm{GO} / \mathrm{CNT}$ actuator can produce approximately twice the tensile actuation force at the same voltage. Therefore, electric stimulus smart actuators can be used as an artificial muscle to imitate the shape deformation of muscle cells. In order to solve the limited multi-function integration problem of most actuators, the large amount of PANI nanoparticles on the surface of GP paper-like actuator was reported, which can provide large pseudocapacitance as power supply units in soft robots (Weng et al., 2020). It had the areal specific capacitance of $402.5 \mathrm{mF} / \mathrm{cm}^{2}$ and bending curvature of $1.03 \mathrm{~cm}^{-1}$ when GP was used for the component layer of actuator and supercapaction electrodes. Furthermore, several researchers are also working on 

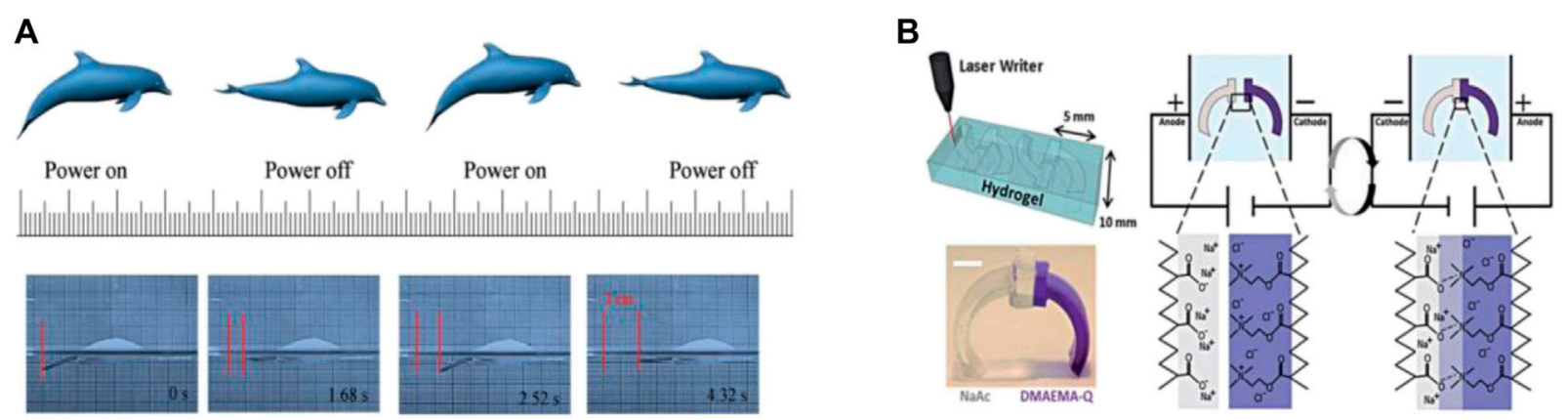

FIGURE 3 | (A) fish-like robot swimming, when the power is on or off, the "tail" bends down or up, then the fish-like robot will swim. Reproduced from Xiao et al. (2016) with permission of WILEY-VCH. (B) Based on the gel electric stimulation of the smart actuator and walking under the electric field drive. Reproduced from Morales et al. (2014) with permission of Royal Society of Chemistry.

biocompatible and multi-functional silk fibroin-based hydrogels (Xu et al., 2019; He et al., 2020). Based on the current effect of electrical stimulation, smart actuators controlled by a variable current (Winchester, 2009) are also essential in capturing nanoparticles. So, the electrical stimulation actuators are compatible with electronic devices and batteries, and if a lower voltage drive can be achieved in the future, it is easy to integrate them with power supplies for using in sensors and industrial automation field.

\section{Smart Actuators Based on Humidity Stimulation Response}

As we all know, humidity stimulus response smart actuators mainly include two kinds of materials: a natural moisture sensitive material, such as agar and silk fiber, and an artificially synthesized materials, such as polyelectrolytes, conductive polymers, hydrogels, and other high molecular polymer materials. Usually, a smart actuator with humidity stimulus response can be prepared by incorporating these materials into a polymer structure. Silk fibers have good mechanical strength, dyeability, which can produce shrinkage rates that are difficult to achieve with other materials (graphene and carbon nanotube fibers). The most important is that they can provide a comfortable wearing experience and respond to humidity for the purpose of managing body temperature. Lin (Lin et al., 2020), Jia (Jia T. et al., 2019), and other researchers (Wang W. et al., 2019; An et al., 2020) adopted a conventional spinning and twisting yarn technology to prepare silk fiber actuators. Studies have shown that these types of actuators can quickly expand and contract by water absorption-induced loss of hydrogen bonds within the silk proteins and the associated structural transformation, as shown in Figure 4A. Among them, the torsional silk muscles provided a fully reversible torsional stroke of $547 \mathrm{~mm}^{-1}$ and $70 \%$ contraction (Jia T. et al., 2019), which is comparable to twisted CNTs fiber actuators that is widely used (Foroughi et al., 2011). And the smart textile woven from silk fiber showed sleeves of smart clothing contracted when exposed to moisture, and recovered to its original length when exposed to dry air. In addition, widely studied GR-based and GO-based actuators usually can only withstand slower bending or rotation motions under moisture stimulation. Therefore, a twisted alginate fiber-based actuator was prepared, this fiber surface transformed from smooth to a stable rough wrinkled structure when water molecules were discharged through twisting, thereby rendering a rapid and reversible rotational expansion and contraction movement (Figure 4B), which achieved a rotation speed of up to $1361 \mathrm{rad} / \mathrm{s}$ and a rotation speed of 400 turns (Wang et al., 2018c). As a new class of green materials, silk fibers and sodium alginate fiber are expected to gradually replace existing GO/GR/CNTs fiber-based actuators due to their merits in terms of low cost and good mechanical strength. So, the humidity responsive torsional artificial muscles utilizing natural textile fibers provide new ideas for natural fibers in the area of smart textile fields. Meanwhile, moisture-sensitive smart actuators based on conductive polymers have also been reported. Wang et al. combined the conductive polymer poly $(3,4-$ ethylenedioxythiophene):polystyrene sulfonate and piezoelectric polymer PVDF by spin coating and thermal evaporation to prepare moisture-sensitive bilayer actuators (Wang G. et al., 2018), which showed a bending angle of over $180^{\circ}$ under moisture stimulation. Moreover, owing to their mechanical displacement at different humidity levels, a generator can be prepared by connecting a piezoelectric device and these actuators, thereby producing a voltage output of $150 \mathrm{mV}$, and charging a capacitor without an energy-draining rectifier circuit, which also provided a new strategy for low-frequency small-signal energy collection and utilization. Recently, as a new 2D material, MXene $\left(\mathrm{Ti}_{3} \mathrm{C}_{2} \mathrm{Tx}\right)$ shows great potential as a smart humidity-responsive actuator due to its high hydrophilicity and conductivity (Wang J. et al., 2020; Nguyen et al., 2020).

\section{Smart Actuators Based on Thermal Stimulation Response}

Thermal responsive actuators can be divided into IR thermal drive, Joule heating drive and thermal radiation drive according to different heat sources. Among them, Joule heat driving is mainly to generate Joule heat inside the conductive material under the action of an external electric field, and then 
A1
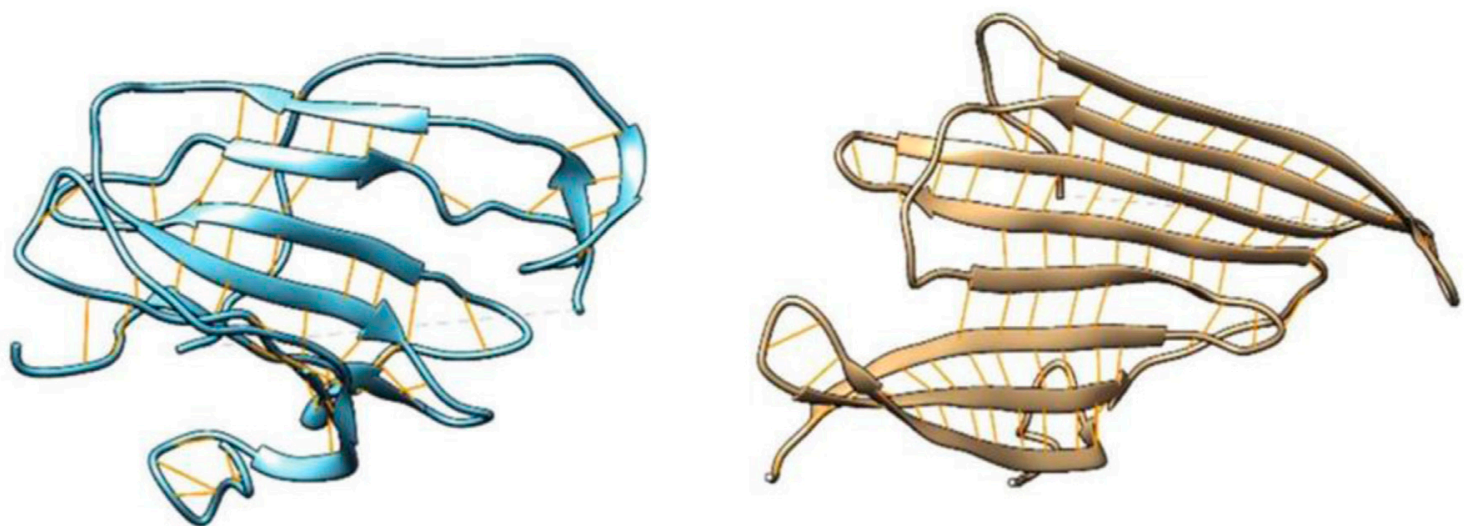

A2
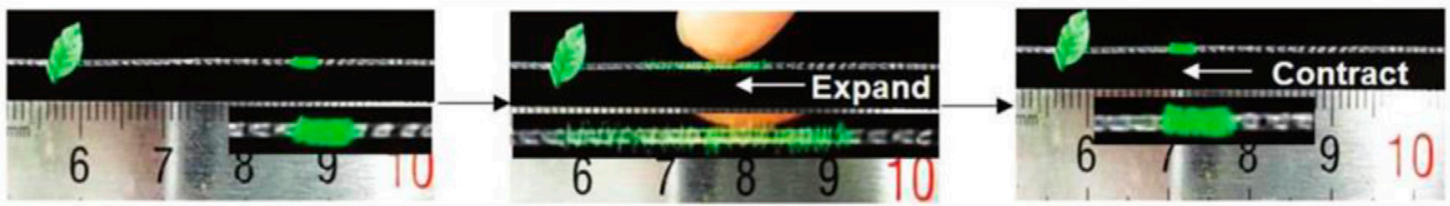

B1

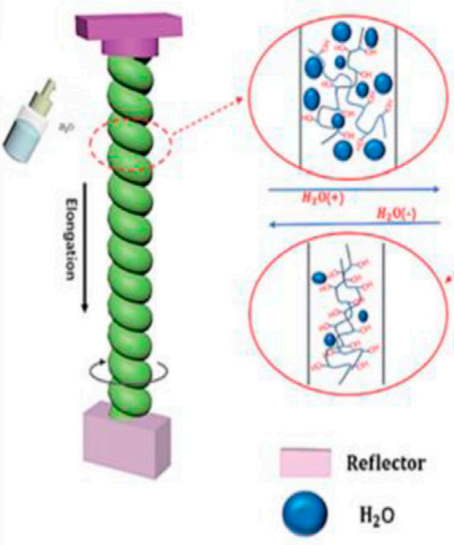

B2

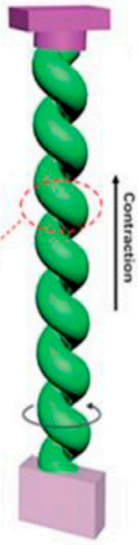

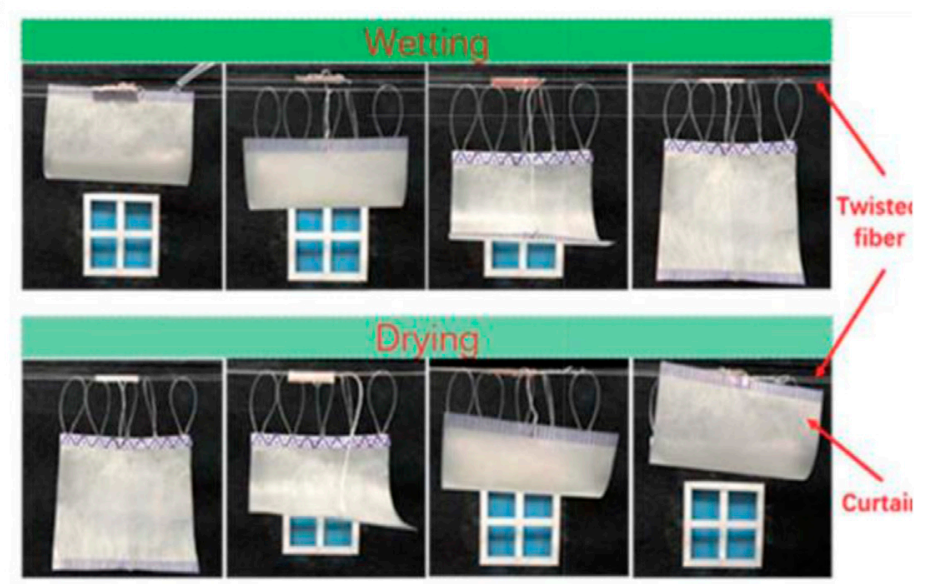

FIGURE 4 | (A1) Molecular dynamic simulation of the proteins before and after water molecules added, the loop structure undergoes transition into a protein secondary structure, and the structure becomes more regular. (A2) a robotic "caterpillar" walking on a barbed wire by moisture stimulation. Reproduced from Jia T. et al. (2019) with permission of WILEY-VCH. (B1) the twisted fiber rapid swelling occurred under water stimulation, leading to fast rotation. After the water evaporated, the fiber quickly returned to its original state. (B2) Schematic diagram of the smart rainy curtain. Reproduced from Wang et al. (2018c) with permission of Royal Society of Chemistry.

promote the material to drive deformation behavior. Thermal radiation driving is generally the driving deformation behavior that occurs under the action of an external heating source. Compared with other stimuli, thermal stimulation is safer and can achieve the corresponding actuation near living cells with the temperature between 4 and $37^{\circ} \mathrm{C}$ (Stroganov et al., 2014). However, the inherent disadvantage of thermal stimulus responsive smart actuators is their lower efficiency than those of different actuators based on other stimuli. In this regard, Jiang et al. photocrosslinked the thermally responsive polymer P(NIPAM-ABP) with TPU to produce a thermal stimulusdriven double layer nanofiber actuator that can quickly, reversibly, and effectively bend within $1 \mathrm{~s}$ at 4 and $40^{\circ} \mathrm{C}$, as shown in Figure 5A (Jiang et al., 2015). In addition, using other non-reactive polymers (such as nylon 6, polysulfonamide) to replace the TPU layer can also achieve thermal stimulus response driving. In contrast to studies that improve heat conversion efficiency using more expensive raw materials, Gao et al. prepared a fiber actuator based on thermal stimulus response using low-cost hollow polyethylene with dual functional response of color and shape change (Gao et al., 2019). A fast shrinkage drive was achieved by improving the heat transfer between the materials through direct Joule heating with a shrinkage of up to $18 \%$ of the original length, thereby providing better advantages in actual industrial production. In order to further improve the response sensitivity of the actuators, Mo et al. used DC electric field to induce the gradient distribution of renewable cellulose nanocrystals (TCNs) in the PNIPAM matrix to fabricate a fast 

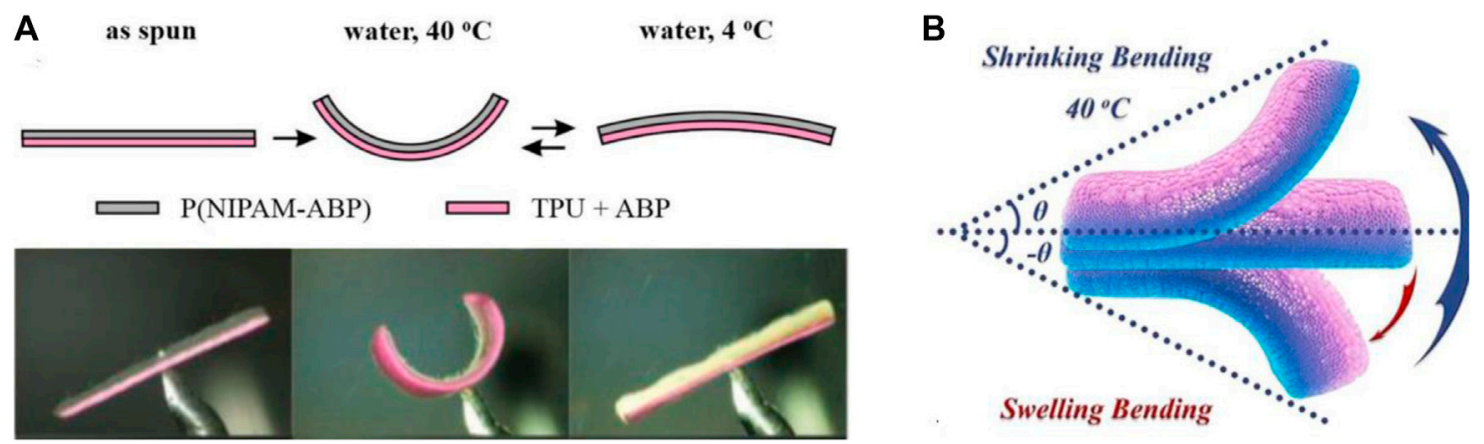

FIGURE 5 | (A) Schematic illustration of shape of bilayer at different temperature conditions. Reproduced from Jiang et al. (2015) with permission of WILEY-VCH. (B) Reversible bending behavior of thermo-responsive hydrogel actuators. Reproduced from Mo et al. (2020) with permission of Royal Society of Chemistry.
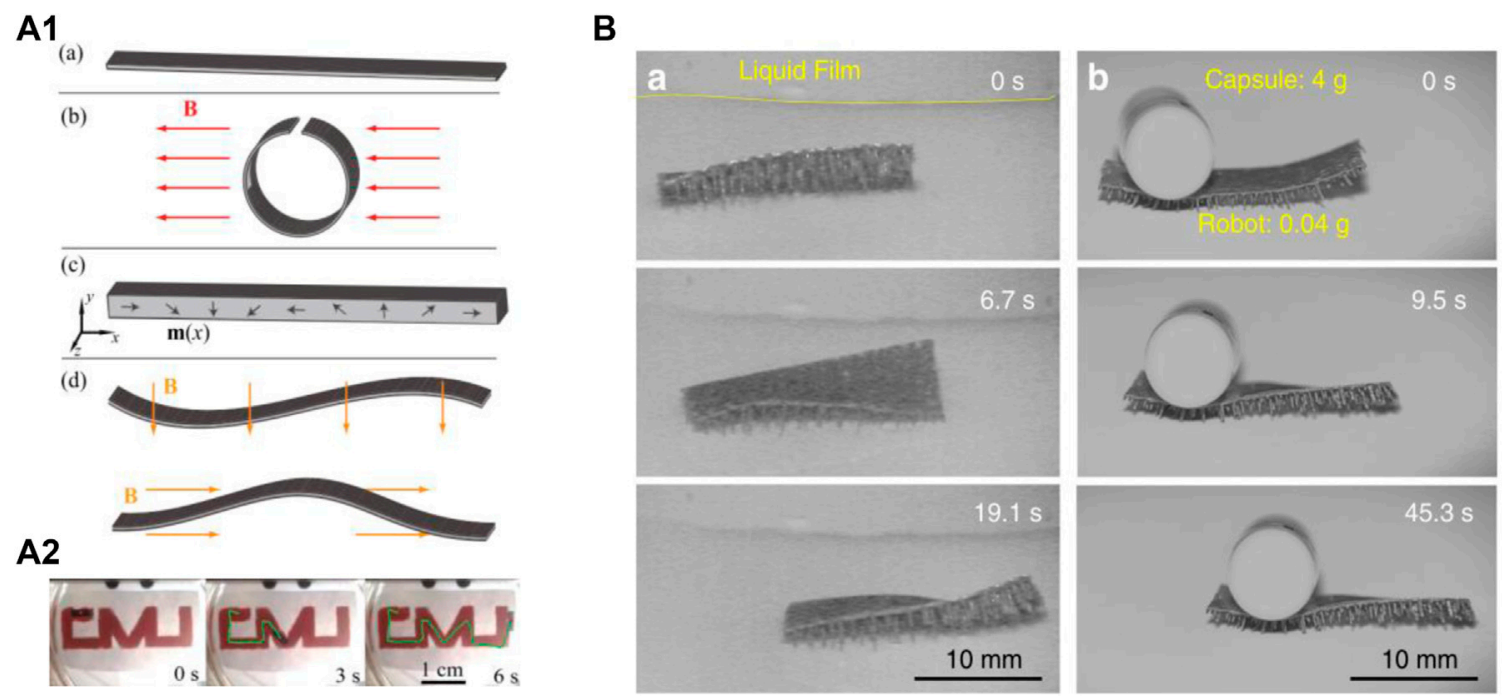

FIGURE 6 | (A1) Continuous-magnetization-profile fabrication method, a direction varying magnetization profile is created by folding the soft materials when it is magnetized. (A2) Controlled path following of the robot on the water surface. Reproduced from Diller et al. (2014) with permission of AlP. (B) The robots move with an average speed of $0.5 \mathrm{~mm} / \mathrm{s}$ on wet surface under a drive frequency of $1 \mathrm{~Hz}$ and move $8 \mathrm{~mm}$ in $45 \mathrm{~s}$ with a loading 100 times of its own weight. Reproduced from Lu $\mathrm{H}$, et al. (2018) with permission of Springer Nature.

thermally responsive hydrogel for high-performance actuators (Mo et al., 2020). which achieved fast bending $\left(4.8^{\circ} / \mathrm{s}\right)$ and recovery $\left(1.4^{\circ} / \mathrm{s}\right)$ at $40^{\circ} \mathrm{C}$ and $25^{\circ} \mathrm{C}$, respectively, with good fatigue resistance (Figure 5B). For thermally responsive smart actuators, increasing their responsiveness will certainly lead to more applications in soft robotics.

\section{Smart Actuators Based on Magnetic Stimulation Response}

Soft and flexible material with magnetic particles can produce a series of shape-controllable bending and deformation behaviors in an external magnetic field. Due to the magnetic particles can make the polymer form an effective magnetic domain with variable size and direction. So, when actuators are subjected to an external magnetic field, the effective magnetic domain will be aligned along the direction of the magnetic field (Heuchel et al., 2015). And the actuator is macroscopically manifested as twisting, stretching, deformation, expansion and bending and other motion behaviors. In addition, since a magnetic field can pass through most materials magnetic stimulus responsive actuators are responsive and easy to manipulate or selfassemble, which considered to be the ideal alternative material for certain specific spatial domains theoretically (Zhao et al., 2012). At present, the research scope and application fields of magnetic responsive actuators are not as extensive as the flexible actuators described above, and they are mostly only combined with flexible polymer material or oriented magnetized to achieve magnetic response drive. Both Diller (Diller et al., 2014) and $\mathrm{Hu}$ ( $\mathrm{Hu}$ et al., 2018) et al. investigated the introduction of $\mathrm{NdFeB}$ into different flexible polymers, and preparation magnetic responsive 

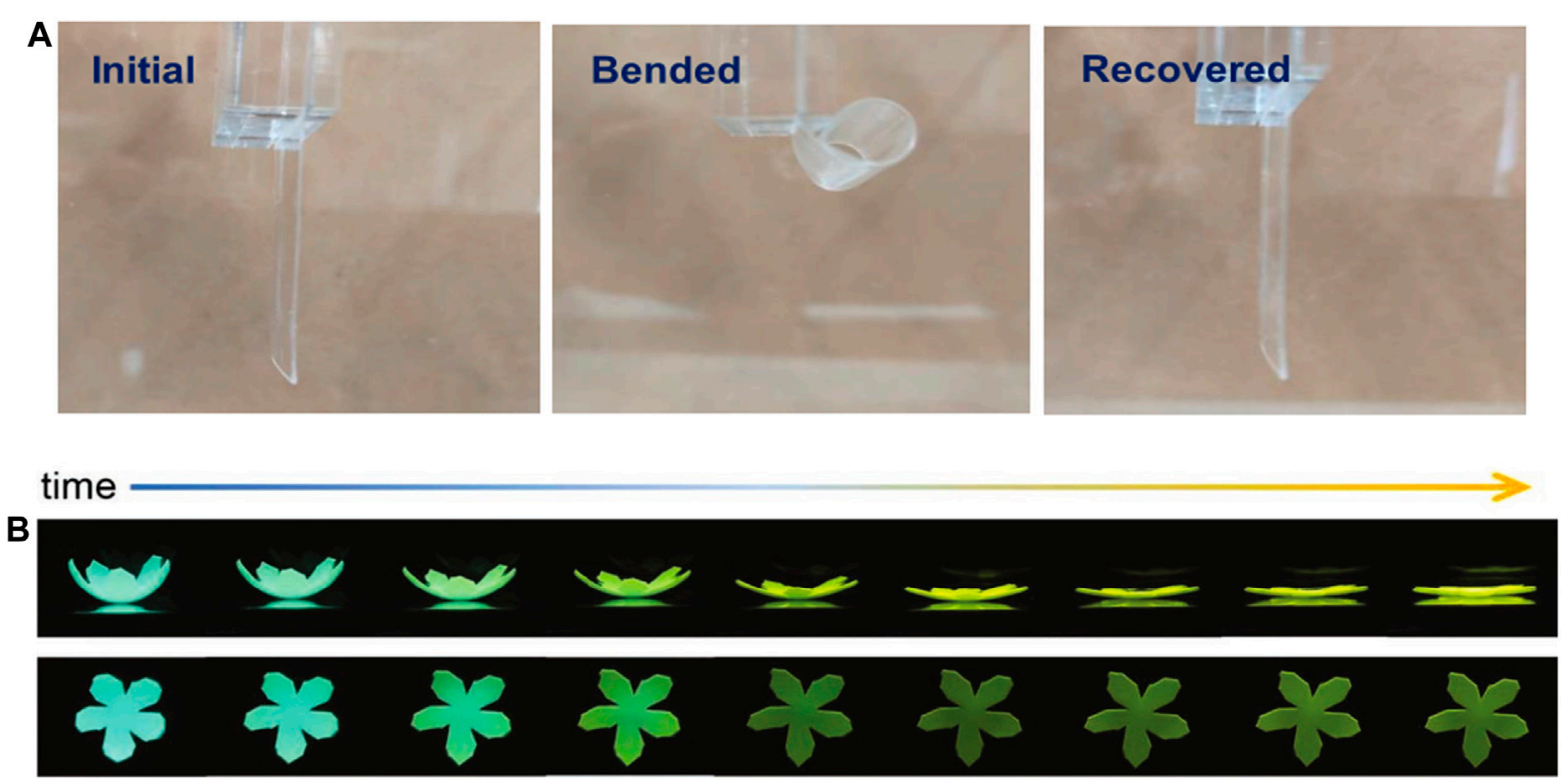

FIGURE 7 | (A) Curling and recovery process of the PDMS film. Reproduced from Zheng et al. (2019) with permission of American Chemical Society. (B) Simultaneous emission change and complex shape deformation of hydrogel actuator. Reproduced from Hubbard et al. (2019) with permission of WILEY-VCH.

flexible actuators with extremely fast responsive speed $(<1 \mathrm{~s})$. Under an external magnetic field, the orientation of the embedded magnetic $\mathrm{NdFeB}$ particles completely aligned with the magnetic field direction and realize directional movement in two or three dimensions direction, as shown in Figure 6A. Lu et al. reported an unbound soft actuator ( $\mathrm{Lu} \mathrm{H}$. et al., 2018), which used a modified magnetic particle-assisted molding method to enable other soft foot architectures with multiple tapered legs controlled by an external magnetic field to exhibit superior adaptability to harsh environments at ultra-fast movements ( $>40 \mathrm{limb}$ length/s), while achieving maximum transfer capability ( $>100$ deadweight) and excellent barrier crossing capability $\left(90^{\circ}\right.$ upright, $>10$ body height over obstacles) (Figure 6B). Similarly, Wang et al. proposed an ultrafast response $(<0.1 \mathrm{~s})$ and precisely controllable soft electromagnet actuator based on Ecoflex rubber film filled with neodymium-iron-boron (Wang X. et al., 2020). Besides, Garstecki et al. reported millimeter-scale robots can also achieve an asymmetrical swimming gait with a maximum speed of $0.3 \mathrm{~mm} / \mathrm{s}$ through a rotating external magnetic field (Garstecki et al., 2009).

\section{Smart Actuators Based on Chemical Stimulation Response}

Chemical stimuli have a relatively wide range of influencing factors, while the response mechanism mainly includes chemical reaction induced deformation, formation and destruction of chemical bonds, and liquid action induced capillary force to produce structural deformation (Grinthal and Aizenberg, 2013). Chemical stimulus responsive driving behavior is mainly through the selective adsorption of chemical solutions by the actuator, or chemical reactions under the action of acids, alkalis, organic solvents, and water vapor to convert chemical energy into mechanical energy (Lindsey et al., 2017). Such as Hore et al. reported an elastomeric actuator, which swelled when organic solvent was added to the surface of the actuator,and thus pushing the actuator upwards with enough force to carry 10 times its own weight (Hore et al., 2012). In general, chemical stimulus actuator tend to be lower sensitive, their response time are on the order of minutes or hours. Furthermore, a small amount of chemical solvent stimulus could not easily trigger a large-scale drive behavior. In that regard, there are many studies are working to reduce the response time from minutes to seconds, $\mathrm{UV} / \mathrm{O}_{3}$-modified PDMS film exhibited a series of fine wrinkles after alcohol vapor absorption for $17 \mathrm{~s}$ (Figure 7A), which can not only adjust the transparency of the film, but generate internal stress that trigger a large spontaneous curling deformation (Zheng et al., 2019). Gestos et al. shown microscale hydrogel fibers actuator achieving actuation strains of $20-100 \%$ and response times down to $5-10 \mathrm{~s}$ with pH between 3 and 8 (Gestos et al., 2012). In addition to monotonous drive changes, the chemical stimulus responsive actuator demonstrated versatile changes. Wang et al. developed an actuator that can bright color shifts and a displacement drive of $1.8 \mathrm{~mm} / \mathrm{s}$ under the stimulation of chloroform, acetone, ethanol, and other organic substances (Wang et al., 2019b). Li et al. demonstrated TPE-4Py/PASbased monolayer hydrogels and bilayer hydrogel actuators, which could simultaneously change its fluorescence color, brightness, and shape in $\mathrm{pH} 3.12$, as shown in Figure $7 \mathbf{B}$ (Li M. et al., 2020). Unlike the traditional preparation of sandwich-structured actuators by using chemical treatments, Hubbard et al. were the first to use glass fiber fabric as the 
TABLE 1 | Feature of multiple response smart actuator based on single stimulus responses

\begin{tabular}{|c|c|c|c|c|}
\hline $\begin{array}{l}\text { Actuation } \\
\text { Method }\end{array}$ & Material & Properties & Application & References \\
\hline \multirow[t]{9}{*}{ Light } & PU and CNTs & $70^{\circ} \mathrm{C}$ NIR, contractive actuation of $6.7 \%(6 \mathrm{~s})$, recovery $(10 \mathrm{~s})$. & Artificial muscle & Meng et al. (2019) \\
\hline & PNIPAM and GO & $0.58 \mathrm{~mW} / \mathrm{cm}^{2} \mathrm{NIR}$, responsive swelling ratio of $6900 \%$ (4 min). & Remote light-controlled devices & Shi et al. (2015) \\
\hline & PNIPAM and GO & 808 nm NIR, shrinkage of 25\% (360 s). & Drug delivery vehicles & Zhang et al. (2019) \\
\hline & PNIPAM, RGO and PAAM & $\begin{array}{l}\text { Visible light } 41.8 \mathrm{~mW} / \mathrm{cm}^{2} \text {, bending to ring }(30 \mathrm{~s}) \text {; recovery } \\
(30 \mathrm{~s}) \text {. }\end{array}$ & Light-responsive actuators & Kim et al. (2016) \\
\hline & $\begin{array}{l}\text { Monoacrylate and } \\
\text { Diacrylate }\end{array}$ & 455 nm NIR, bending of 20 mm (3 s),recovery (8 s). & Light-driven transportation & $\begin{array}{l}\text { Pilz da Cunha et al. } \\
\text { (2020) }\end{array}$ \\
\hline & GO and PC & $\begin{array}{l}\text { NIR } 106 \mathrm{~mW} / \mathrm{cm}^{2} \text {, response time }(<1 \mathrm{~s}) \text {, bending of } 12 \mathrm{~mm} \\
(3 \mathrm{~s}) \text {, bending curvature of } 0.33 \mathrm{~cm}^{-1} \text {, recovery }(5 \mathrm{~s}) .\end{array}$ & $\begin{array}{l}\text { IR and sunlight-driven smart curtain, } \\
\text { self-folding box. }\end{array}$ & $\begin{array}{l}\text { Leeladhar et al. } \\
\text { (2018) }\end{array}$ \\
\hline & Sodium acrylate and IONP & $\begin{array}{l}2.34 \mathrm{~W} \text {, take-off speed of } 1.6 \mathrm{~m} / \mathrm{s}(800 \mathrm{~ms}) ; 0.67 \mathrm{~W} \text {, rolling } \\
\text { velocity of } 10 \mathrm{~cm} / \mathrm{s}(1.3 \mathrm{~s})\end{array}$ & cargo delivery robotics & Li et al. (2020b) \\
\hline & PET and Xylene & UV $170 \mathrm{~mW} / \mathrm{cm}^{2}$, bending of $19 \mathrm{~cm}$ (14 s), recovery (4 s). & soft robotic & $\begin{array}{l}\text { Verpaalen et al. } \\
(2020)\end{array}$ \\
\hline & PU, MDA and DAB & $385 \mathrm{~nm}$ UV, $100 \mathrm{~mW} / \mathrm{cm}^{2}$, bending angle of $70^{\circ}(50 \mathrm{~s})$ & Self-healable PME actuators & Li et al. (2019b) \\
\hline \multirow[t]{6}{*}{ Electrical } & GR and PVDF & $\begin{array}{l}13 \mathrm{~V} \text {, bending of } 14 \mathrm{~mm}(0.26 \mathrm{~s}) ; 17 \mathrm{~V} \text {, Driving stress of } 312.7 \\
\mathrm{MPa} / \mathrm{g} \text {, movement speed of } 5.02 \mathrm{~mm} / \mathrm{s} \text {. }\end{array}$ & High-performance power generator & Zhao et al. (2016) \\
\hline & $\begin{array}{l}\text { AAm, NaAc and } \\
\text { DMAEMA-Q }\end{array}$ & $\begin{array}{l}5 \mathrm{~V} / \mathrm{cm} \text { electric field, Bending curvature of } 0.28 \mathrm{~mm}^{-1}(150 \mathrm{~s}) \text {, } \\
\text { movement speed of } 2.5 \mathrm{~mm} / \mathrm{min} \text {. }\end{array}$ & Micro-robotics & Xiao et al. (2016) \\
\hline & Graphadiyne and PVDF & $\begin{array}{l}2.5 \mathrm{~V} \text {, electromechanical transduction efficiency of } 6.03 \% \text {, } \\
\text { bending displacement of } 16 \mathrm{~mm} \text {. }\end{array}$ & Electro-actuation gel walker & Morales et al. (2014) \\
\hline & GR and CNTs & $20 \mathrm{mV} / \mathrm{s}$ voltage, tensile actuation of $19 \%$. & Micromechanical robotics & Hyeon et al. (2019) \\
\hline & GR and PANI & $\begin{array}{l}2.5 \mathrm{~V} \text {, Bending curvature of } 1.03 \mathrm{~cm}^{-1}(5 \mathrm{~s}) \text {, areal specific } \\
\text { capacitance of } 402.5 \mathrm{mF} / \mathrm{cm}^{2} \text {. }\end{array}$ & Multi-functional actuator & Weng et al. (2020) \\
\hline & CNTs and TEA.BF4/PC & $\begin{array}{l}20 \mathrm{mV} / \mathrm{s} \text { voltage, tensile actuation of } 16.5 \% \text {, electromechanical } \\
\text { transduction efficiency of } 5.4 \% \text {. }\end{array}$ & Artificial muscles & Lee et al. (2017) \\
\hline \multirow[t]{6}{*}{ Humidity } & A. pernyi silk & $\begin{array}{l}\mathrm{RH} 43 \% \text {, rotation speed of } 6179.3^{\circ} / \mathrm{s}(4.8 \mathrm{~s}) \text {, actuation power of } \\
2.1 \mathrm{~W} / \mathrm{kg} \text {, contractive actuation of } 10 \% \text {. }\end{array}$ & Water-induced micro-actuators & Lin et al. (2020) \\
\hline & Bombyx raw silk fiber & $\begin{array}{l}\mathrm{RH} 20 \% \text { to } 80 \%, 70 \% \text { contraction, reversible torsional stroke of } \\
547 \mathrm{~mm}^{-1}\end{array}$ & Smart textiles and soft robotics. & Jia et al. (2019b) \\
\hline & Sodium alginate & $\mathrm{RH} 90 \%$, rotation speed of 13000 rpm (5.44 s). & $\begin{array}{l}\text { Hydro-generator and breathable } \\
\text { fabric }\end{array}$ & Wang et al. (2018c) \\
\hline & PEDOT: PSS and PVDE & $\mathrm{RH} 23 \%$ to $86 \%$, Bending angle of $191^{\circ}$ to $225^{\circ}$. & Generator and bionic field & Wang et al. (2018a) \\
\hline & $\mathrm{CS}$ and $\mathrm{GO}$ & $\mathrm{RH} 45 \%$, Bending angle of $180^{\circ}$ (4 s). & sensors & Zhang et al. (2017) \\
\hline & MXene nanosheet & $\mathrm{RH} 65 \%$, Bending angle of $155^{\circ}$ & $\begin{array}{l}\text { flexible excavators and electrical } \\
\text { switches }\end{array}$ & Wang et al. (2020a) \\
\hline \multirow[t]{4}{*}{ Heat } & $\begin{array}{l}\mathrm{P}(\mathrm{NIPAM}-\mathrm{ABP}), \mathrm{ABP} \\
\text { and TPU }\end{array}$ & $40^{\circ} \mathrm{C}$, bend to ring $(1 \mathrm{~s}), 4^{\circ} \mathrm{C}$, recovery. & $\begin{array}{l}\text { Porous 3D bioscaffolds and } \\
\text { electrodes }\end{array}$ & Jiang et al. (2015) \\
\hline & $\mathrm{H}-\mathrm{PE}$ & $60^{\circ} \mathrm{C}$, discoloration, multiple curls ( $\left.3 \mathrm{~s}\right), 18 \%$ contraction. & Artificial muscles & Gao et al. (2019) \\
\hline & PNIPAM and TCNC & $40^{\circ} \mathrm{C}$, bending speed of $4.8^{\circ} / \mathrm{s}, 25^{\circ} \mathrm{C}$, recovery speed of $1.4^{\circ} / \mathrm{s}$. & $\begin{array}{l}\text { Temperature-controlled } \\
\text { manipulators }\end{array}$ & Mo et al. (2020) \\
\hline & CNTs, xLCE and PIM & $120^{\circ} \mathrm{C}$, bending curvature of $1 \mathrm{~mm}^{-1}(20 \mathrm{~s})$, recovery (5 s). & $\begin{array}{l}\text { Restoration of deformed dynamic } \\
\text { 3D actuators }\end{array}$ & Yang et al. (2016) \\
\hline \multirow[t]{3}{*}{ Magnetic } & $\begin{array}{l}\text { NdFeB and platinum-cure } \\
\text { silicon rubber }\end{array}$ & $\begin{array}{l}1 \mathrm{~Hz}, 2 \mathrm{mT} \text {, bending drive response }(0.75 \mathrm{~s}), 30 \mathrm{~Hz}, 5 \mathrm{mT} \text {, } \\
60 \mathrm{~mm} / \mathrm{s}, 2.5 \mathrm{mT}, 50 \mathrm{~Hz}, 100 \mathrm{~mm} / \mathrm{s} \text {. }\end{array}$ & Micro-robotics in biotechnology & Diller et al. (2014) \\
\hline & $\begin{array}{l}\text { NdFeB and silicone } \\
\text { elastomer }\end{array}$ & $17 \mathrm{mT}$, bending drive response (40 ms). & Soft millimetre-scale robots & Hu et al. (2018) \\
\hline & $\begin{array}{l}\text { PDMS and iron } \\
\text { microparticles }\end{array}$ & $200 \mathrm{mT}$, displacement of $1.2 \mathrm{~mm}$, deflection angle of 18 (0.5 s). & Bio-inspired robotics & Lu et al. (2018b) \\
\hline \multirow[t]{6}{*}{ Chemical } & TMPTA and DEPA & $\begin{array}{l}\text { Ammonia-acetone vapor, displacement drive of } 1.8 \mathrm{~mm} / \mathrm{s} \text {, } \\
\text { dynamic color change of } 0.16 \mathrm{~cm} / \mathrm{s} \text {. }\end{array}$ & $\begin{array}{l}\text { Self-powered actuators and } \\
\text { grippers }\end{array}$ & Zheng et al. (2019) \\
\hline & TPE-4Py and PAS & $\begin{array}{l}\text { PH3.12, Semi-circular arc expands to parallel shape and color } \\
\text { change ( } 400 \mathrm{~min}) \text {. }\end{array}$ & $\begin{array}{l}\text { Soft robotics with communication, } \\
\text { sensing, and disguise }\end{array}$ & Wang et al. (2019b) \\
\hline & PDMS, PA and GF & $\begin{array}{l}\text { Acetone, deflection angle of } 48^{\circ}(10 \mathrm{~min}), 2.0 \mathrm{M} \mathrm{NaCl} \text {, } \\
\text { convex (24 h). }\end{array}$ & $\begin{array}{l}\text { Artificial muscles and triple-state } \\
\text { actuators. }\end{array}$ & $\begin{array}{l}\text { Hubbard et al. } \\
\text { (2019) }\end{array}$ \\
\hline & PFSA and PET & $\begin{array}{l}18 \% \text { Ethanol vapor, bending curvature of } 0.31 \mathrm{~mm}^{-1} \text { Deflection } \\
\text { angle of } 180^{\circ}(0.25 \mathrm{~s}) .\end{array}$ & $\begin{array}{l}\text { Soft actuator with multicolor } \\
\text { switching capability }\end{array}$ & Mu et al. (2018) \\
\hline & PCMVImTf $2 \mathrm{~N}$ and PAA & $1.5 \mathrm{~mol} \%$ acetone, bending curvature of $0.38 \mathrm{~mm}^{-1}$. & $\begin{array}{l}\text { Smart and sensitive signaling micro- } \\
\text { robotics }\end{array}$ & Zhao et al. (2015) \\
\hline & Lignin and PEGDGE & $\begin{array}{l}0.1 \mathrm{M} \mathrm{HCl} \text { and } \mathrm{KOH} \text {, response speed }\left(8.0^{\circ} / \mathrm{s}\right) \text { and recovery } \\
\left(6.5^{\circ} / \mathrm{s}\right) \text {, }\end{array}$ & Flow control valve and smart hook & Dai et al. (2020) \\
\hline
\end{tabular}



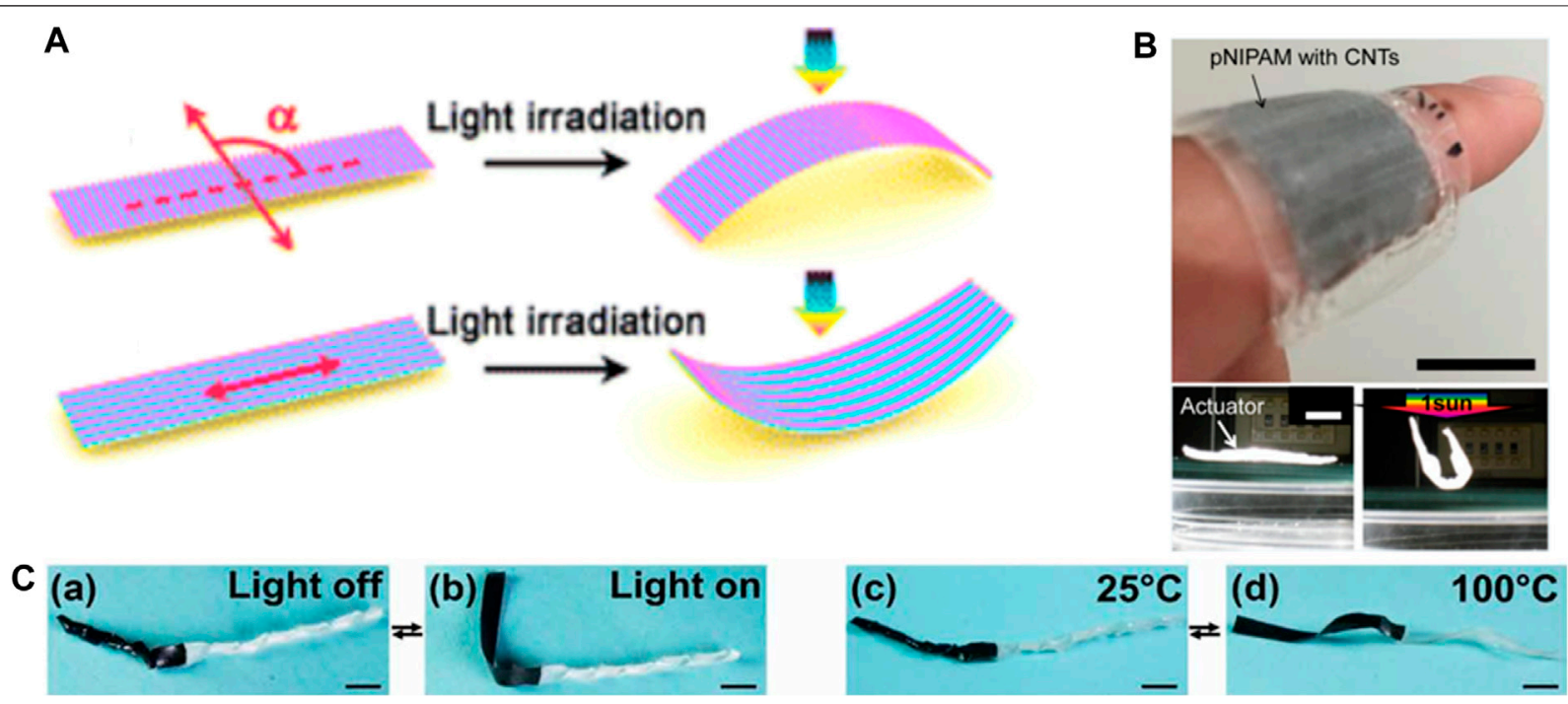

FIGURE 8 | (A) Schematic illustration of the apheliotropic and phototropic bending of the composite strips with different aligned directions of smart actuator. Reproduced from Deng et al. (2015) with permission of American Chemical Society. (B) Demonstrations of the PNIPAM actuators stimulated by the human skin temperature and sunlight. Reproduced from Yamamoto et al. (2015) with permission of American Chemical Society. (C) Schematic showing of an area-selective reversible multiresponsive actuator. Reproduced from Zhang Y. et al. (2020) with permission of American Association for the Advancement of Science.

intermediate bonding phase between PDMS elastomers and polyampholytic electrolyte hydrogels, resulting in enhanced mechanical properties and better bonding of these two chemically different materials, with a bonding energy of up to $1000 \mathrm{~N} / \mathrm{m}$ (Hubbard et al., 2019). This actuator achieved reversible bending behavior in salt solutions and organic solvents (e.g., acetone solutions) with drive stresses of up to $40 \%$ of the human skeletal muscle and provided new insights on the interfacial crosslinking instability common to multistructural actuators. In addition, the combination of chemical stimulation and $3 \mathrm{D} / 4 \mathrm{D}$ printing technology allows the easy manufacturing of arbitrarily complex configurations, such as carton panels (Zheng et al., 2018) and the "Sydney Opera House" (Huang et al., 2017). So, the anisotropic hydrogel actuator based on chemical stimulation response provides good selectivity for biological actuators, flexible robots, and other intelligent bionic device applications.

The main research progress of smart actuators based on single stimulation response is summarized in Table $\mathbf{1}$.

\section{MULTIPLE STIMULI RESPONSE SMART ACTUATORS}

Although single stimulus response smart actuator can be precisely controlled and has a relatively simple preparation, the actual environment is highly diverse and complex with more than a single stimulus source. Therefore, single stimulus response or simple functional output of the above smart actuators are no longer sufficient for the current actuation requirements in complex environments. The development of newer stimulus conditions and diversified stimulus methods has become an urgent requirement for stimulus-responsive smart actuators (Wang T. et al., 2018). Generally, multi-stimulus response smart actuators are mainly constructed by introducing multifunctional stimulus responsive groups into polymeric materials, achieving multi-responsive properties through precise molecular design or blending methods (Deng et al., 2015) (Cheng et al., 2016).

\section{Smart Actuator Based On Dual Light And Heat Stimuli Response}

Currently, some photo-thermal conversion effect materials (GR, GO, CNTs, PDA) are added to some thermally responsive shape memory polymer materials, which can produce thermal effects under the irradiation of light to achieve light/thermal dual stimulation. Among them, PA6 has high spinnability and hygroscopicity, the fiber actuators with spiral structures and light/heat response can be obtained by electrospinning and twisting treatment. Huang et al. (Huang et al., 2020) added PDA before twisting, resulting in a driving stress of approximately $0.9 \mathrm{MPa}$ and shrinkage rate of $5.1 \%$ under NIR light and $180^{\circ} \mathrm{C}$. Yamamoto et al. combined CNTs with PNIPAM as photothermal conversion materials of their prepared actuators that could achieve a bending deflection of $210^{\circ}$ within $80 \mathrm{~s}$ under photothermal stimulation (Figure 8B) (Yamamoto et al., 2015). However, its response time was lower than that of the PNIPAM/GO photothermal response actuator prepared by in situ polymerization and centrifugal method (He et al., 2019), which could also achieve rapid and controllable bidirectional bending within 30 s. In addition, the doublelayer thin-film smart actuator composed of paraffin wax and CNTs 

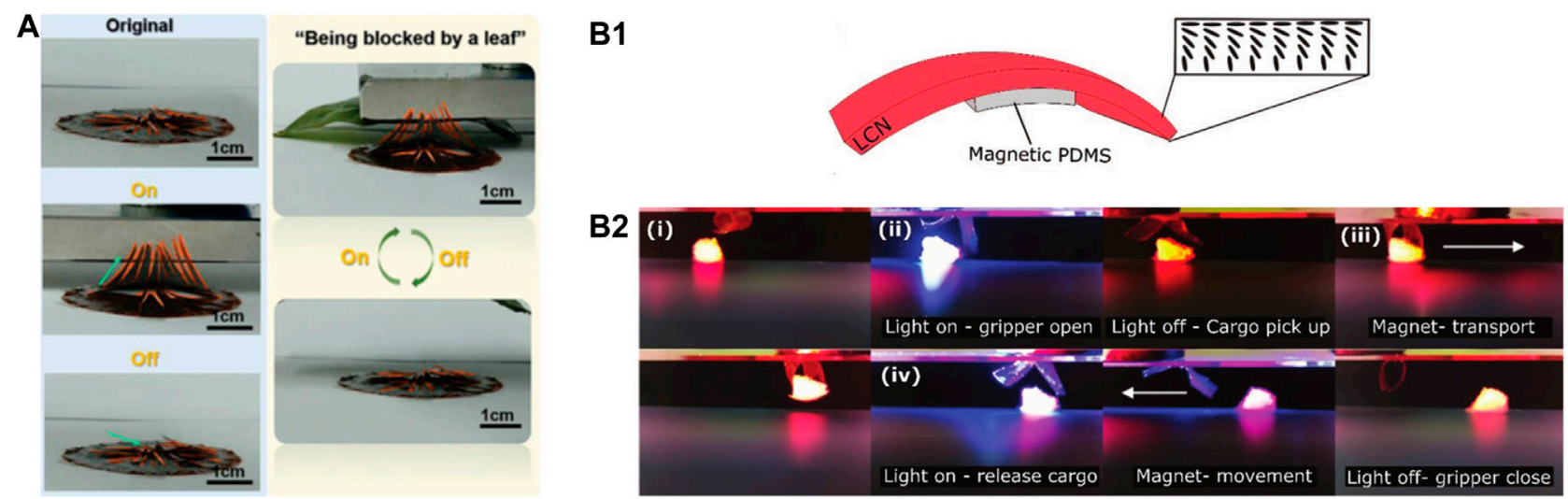

FIGURE 9 | (A) Photographs of a "mimosa pudica" splaying and closing, and morphing blocked by a leaf and exposed to magnetic field, respectively. Reproduced from Wang et al. (2019c) with permission of WILEY-VCH. (B1) Magneto-light responsive actuator with localized PDMS/Fe composite layer coated on LCN. (B2) The untethered pick up, transport, and release of a cargo, performed by the dual-responsive gripper within an enclosed space. Reproduced from Pilz da Cunha et al. (2019) with permission of WILEY-VCH.

can also achieve the corresponding dual stimulus response bending behavior (Deng et al., 2016) (Figure 8A). $\mathrm{MoS}_{2}$ nanosheets can enable the actuator to achieve adjustable light and heat response drives when incorporated in hydrogel carboxyl chitosan as light and heat transfer agent (Lei et al., 2016). The anisotropic structure of the actuator allowed good shape deformation and self-wrapping kinematic properties by the remote control of NIR light or temperature of $70^{\circ} \mathrm{C}$ and recovery to its initial state in a relatively short time at room temperature. Meanwhile, Zhang et al. proposed that different types of liquid crystal elastomer materials can be crosslinked with functional media while being oriented to prepare composite flexible actuators with different driving modes under light and thermal stimulation, showing the highest driving strain (Figure 8C) (Zhang Y. et al., 2020). This kind of light/heat dual stimulus responsive actuators will have broad development prospects in smart machinery and other fields.

\section{Smart Actuator Based on Dual Light and Electric Stimuli Response}

Smart actuators based on light and electric stimuli response can be prepared by combining light-sensitive materials with electroactive polymers. However, a common problem is lower curvature for such actuators (Seo et al., 2012). Therefore, Yang et al. (Wei et al., 2020) reported a sericin functionalized RGO (SRGO)/ PI double layer actuator with light and thermal stimuli response by directly coating RGO paper on PI tape. Owing to the deformation of the micro-airbags in the SRGO layer and thermal expansion of the PI layer, the actuator can achieve bending deformations of $0.55 \mathrm{~cm}^{-1}$ under $16 \mathrm{~V}$ or light stimulation. The photo-mechanical drive and triboelectric effect of the integrated SRGO/PI double layer actuator was used to assemble a photoelectric generator. Similarly, Weng et al. also prepared a light-electric dual stimulus-response actuator based on high-efficiency conduction of GR and thermal conversion effects, which can produce up to $2.6 \mathrm{~cm}^{-1}$ bending drive behavior for NIR light and electrical stimulation (Weng et al., 2016).

\section{Smart Actuator Based on Dual Light and Magnetic Stimuli Response}

Generally, opto-magnetic response actuators can be simply obtained by incorporating magnetic nanoparticles to a lightresponsive actuator (Cheng et al., 2017; Gelebart et al., 2017). Such as, $\mathrm{Fe}_{3} \mathrm{O}_{4} \mathrm{NPs}$ can make composite materials magnetic, Wang et al. introduced $\mathrm{Fe}_{3} \mathrm{O}_{4} / \mathrm{CNC}$ nanocrystal nanohybrids as the response medium to presents a superfast magnetic response of $0.36 \mathrm{~s}$ and light response of $0.44 \mathrm{~s}$ (Wang et al., 2019c), as shown in (Figure. 9A). The metal ligand coordination between $\mathrm{Fe}_{3} \mathrm{O}_{4}$ NPs and the catechol groups of DOPAC achieved an ultra-high photothermal conversion efficiency of $79.1 \%$ by crosslinking interfacial supramolecule and DOPAC acid. However, Han et al. asymmetrically distributed $\mathrm{Fe}_{3} \mathrm{O}_{4}$ NPs in RGO to alter their water absorption capacity, resulting in the stimulus responses to light, heat, water, and magnetic conditions (Han et al., 2020). This also solved the problem of interlayer separation in a dual piezoelectric wafer actuator. Furthermore, the flower-shaped actuator could perform a simple co-bending drive in a complex environment, where multiple stimuli simultaneously exist. Recently, Pilz et al. combined PDMS layer functionalized with carbonyl magnetic iron powder and the LCN containing a photosensitive azobenzene dye, as shown in Figure 9B, which achieved a breakthrough in the uniformity of the drive under dual stimulation in the same space (Pilz da Cunha et al., 2019). The azobenzene derivative was rapidly isomerized and generating heat to realize the bending and capturing behavior of the actuator under light stimulation, while the magnetic response was used as a magnetic guide to drive the actuator with translational and rotational degrees of freedom (Figure 9B).

\section{Smart Actuator Based on Dual Heat and Chemical Stimuli Response}

Since the ionizable acid groups in PAA hydrogel can accept and deliver protons in response to changes in $\mathrm{pH}$. Thus, Shang et al. added PNIPAM with a high expansion and temperature 
TABLE 2 | Feature of multiple response smart actuator based on multiple stimulus responses

\begin{tabular}{|c|c|c|c|c|}
\hline $\begin{array}{l}\text { Actuation } \\
\text { Method }\end{array}$ & Material & Properties & Application & References \\
\hline \multirow[t]{7}{*}{ Light/Heat } & PA6 and pDA & $\begin{array}{l}180^{\circ} \mathrm{C} \text {, contractive actuation of } 5.1 \% \text {. NIR, contractive } \\
\text { actuation of } 3.2 \% \text {. }\end{array}$ & Artificial muscle & Huang et al. (2020) \\
\hline & MoS2 and Carboxyl & $70^{\circ} \mathrm{C}, 5 \mathrm{~W} / \mathrm{cm}^{2} \mathrm{NIR}$, bending curvature of $0.23 \mathrm{~cm}^{-1}(70 \mathrm{~s})$ & Flexible anisotropic actuator & Lei et al. (2016) \\
\hline & PNIPAM and CNTs & $\begin{array}{l}\left.50^{\circ} \mathrm{C} \text {, bending angle of } 210^{\circ} \text { ( } 80 \mathrm{~s}\right) .100 \mathrm{~mW} / \mathrm{cm}^{2} \text { light, } \\
\text { bending angle of } 210^{\circ}(14 \mathrm{~min}) .\end{array}$ & $\begin{array}{l}\text { Wearable device and natural power source } \\
\text { actuator }\end{array}$ & $\begin{array}{l}\text { Yamamoto et al. } \\
(2015)\end{array}$ \\
\hline & $\begin{array}{l}\text { PNIPAAm, BIS and } \\
\text { PBPO }\end{array}$ & $\begin{array}{l}\left.35^{\circ} \mathrm{C} \text {, bending curvature of } 5.2 \mathrm{~cm}^{-1} \text { ( } 7 \mathrm{~min}\right) .665 \mathrm{nmUV} \text {, } \\
\text { red fluorescence appears. }\end{array}$ & $\begin{array}{l}\text { Biomimetic devices, gripper, and } \\
\text { information storage }\end{array}$ & $\begin{array}{l}\text { Zhang et al. } \\
\text { (2020b) }\end{array}$ \\
\hline & PNIPAM and GO & $\begin{array}{l}55^{\circ} \mathrm{C} \text {, bending angle of } 210^{\circ}(16 \mathrm{~s}) .2 .5 \mathrm{~W} / \mathrm{cm}^{2} \mathrm{NIR} \text {, curl to } \\
\text { closed state }(17 \mathrm{~s}) .\end{array}$ & Remotely controlled microgrippers & He et al. (2019) \\
\hline & $\mathrm{GO}$ and $\mathrm{MAB}$ & $100^{\circ} \mathrm{C}$, reversible spiral bending. NIR, Curly flattening. & $\begin{array}{l}\text { 3D machine- and animal-mimicking LCE } \\
\text { actuators }\end{array}$ & $\begin{array}{l}\text { Zhang et al. } \\
\text { (2020d) }\end{array}$ \\
\hline & $\begin{array}{l}\text { EDDET, PMMS and } \\
\text { PETMP }\end{array}$ & $\begin{array}{l}90^{\circ} \mathrm{C} \text {, bending angle of } 80^{\circ} .0 .8 \mathrm{~W} / \mathrm{cm}^{2} \mathrm{NIR} \text {, bending } \\
\text { angle of } 110^{\circ}(15 \mathrm{~s}) .80 \mathrm{~W} / \mathrm{cm}^{2} \mathrm{UV} \text {, bending angle of } 100^{\circ} \\
\text { (11 s). }\end{array}$ & $\begin{array}{l}\text { Artificial plants, and multiple-responsive } \\
\text { microrobots }\end{array}$ & $\begin{array}{l}\text { Zhang et al. } \\
\text { (2020a) }\end{array}$ \\
\hline \multirow[t]{3}{*}{ Light/ Electricity } & $\mathrm{RGO}$ and $\mathrm{PI}$ & $\begin{array}{l}16 \mathrm{~V} \text { bending curvature of } 0.55 \mathrm{~cm}^{-1}(5 \mathrm{~s}) .300 \mathrm{~mW} / \mathrm{cm}^{2} \\
\text { light, bending curvature of } 0.45 \mathrm{~cm}^{-1}(10 \mathrm{~s}) .\end{array}$ & Electrothermal actuator, microfluidics & Seo et al. (2012) \\
\hline & GR and BOPP & $\begin{array}{l}10 \mathrm{~V} \text { bending curvature of } 2.6 \mathrm{~cm}^{-1} .300 \mathrm{~mW} / \mathrm{cm}^{2} \mathrm{NIR} \text {, } \\
\text { bending curvature of } 1.9 \mathrm{~cm}^{-1}(10 \mathrm{~s}) .\end{array}$ & $\begin{array}{l}\text { Biomimetic flower, and smart household } \\
\text { materials. }\end{array}$ & Weng et al. (2016) \\
\hline & SWCNT and PE & $\begin{array}{l}9.0 \mathrm{~V} \text {, bending curvature of } 7.8 \mathrm{~cm}^{-1}(3 \mathrm{~s}) . \mathrm{NIR} 250 \mathrm{~mW} / \\
\mathrm{cm}^{2} \text {, bending curvature of } 5.0 \mathrm{~cm}^{-1}(3 \mathrm{~s}) .\end{array}$ & Walking device, smart mechanical devices & Li et al. (2018) \\
\hline \multirow[t]{3}{*}{ Light/magnetic } & $\begin{array}{l}\text { PU, DOPAC and } \\
\text { Fe3O4NPS }\end{array}$ & $\begin{array}{l}\text { Maximum bending angle, } 808 \mathrm{~nm} \text { NIR }(0.44 \mathrm{~s}) \text {. magnetic } \\
\text { field }(0.36 \mathrm{~s}) \text {. }\end{array}$ & Bionic motion robots & $\begin{array}{l}\text { Wang et al. } \\
\text { (2019c) }\end{array}$ \\
\hline & Fe3O4NPs and GO & $\begin{array}{l}200 \mathrm{~mW} / \mathrm{cm}^{2} \text { light, bending angle of } 210^{\circ} \text { (30 s). NdFeB } \\
\text { Magnetic field, bending angle of } 90^{\circ}(3 \mathrm{~s}) .\end{array}$ & Multi-form actuators with different fields & Han et al. (2020) \\
\hline & $\begin{array}{l}\text { PDMS, DCM and } \\
\text { Acrylate }\end{array}$ & $\begin{array}{l}225 \mathrm{~mW} / \mathrm{cm}^{-2} \text { light. Deflection displacement of } 14 \mathrm{~mm} \\
\text { (10 s). Magnetic field, grasping or bending behavior. }\end{array}$ & $\begin{array}{l}\text { Dual-responsive gripper, soft robotics with } \\
\text { programmed }\end{array}$ & $\begin{array}{l}\text { Pilz da Cunha et al. } \\
\text { (2019) }\end{array}$ \\
\hline \multirow[t]{8}{*}{ Heat/chemical } & PNIPAM and PAA & $\begin{array}{l}2^{\circ} \mathrm{C} \text { and } 50^{\circ} \mathrm{C}, \mathrm{PH} 2 \text { and } \mathrm{PH} 11 \text {, two-way bending, } \\
\text { bidirectional bending drive }\end{array}$ & $\begin{array}{l}\text { Temperature-induced self-bending } \\
\text { actuators }\end{array}$ & $\begin{array}{l}\text { Shang and Theato } \\
\text { (2018b) }\end{array}$ \\
\hline & $\begin{array}{l}\text { PNIPAM, CEA } \\
\text { and MBA }\end{array}$ & $\begin{array}{l}\text { Ethanol solution, bending curvature of } 1.4 \mathrm{~cm}^{-1}(90 \mathrm{~s}) \text {. } \\
\mathrm{PH} \text {, bending curvature of } 1.75 \mathrm{~cm}^{-1}(45 \mathrm{~min}), \mathrm{PH} 8 \text {, } \\
\text { recovery ( } 20 \mathrm{~min}) .50^{\circ} \mathrm{C} \text {, bending curvature of } 1.55 \mathrm{~cm}^{-1} \text {. }\end{array}$ & $\begin{array}{l}\text { Anisotropy-encoded hydrogel actuators, } \\
\text { dual-responsive grippers }\end{array}$ & Odent et al. (2019) \\
\hline & $\begin{array}{l}\text { PDADMAC, PNIPAM } \\
\text { and PDMS }\end{array}$ & $\begin{array}{l}25^{\circ} \mathrm{C} \text { and } 40^{\circ} \mathrm{C}, \mathrm{PH} 6.5 \text { and } \mathrm{PH} 3 \text {, downward spherical } \\
\text { bending to upward bending, shrinkage rate } 60 \%(10 \mathrm{~min}) \text {. }\end{array}$ & $\begin{array}{l}\text { Stimulus-induced grippers, biomedical } \\
\text { applications field }\end{array}$ & Li et al. (2017a) \\
\hline & $\begin{array}{l}\text { P(NIPAM-COAAC) } \\
\text { and NaAlg }\end{array}$ & $50^{\circ} \mathrm{C}, 1 \mathrm{M} \mathrm{CaCl} 2$, Shrinkage deformation rate $20 \%(200 \mathrm{~s})$. & Chemical sensors, microengineering & $\begin{array}{l}\text { Yoshida et al. } \\
\text { (2018) }\end{array}$ \\
\hline & $\mathrm{SMA}, \mathrm{AA}$ and $\mathrm{QCH}$ & $\begin{array}{l}80^{\circ} \mathrm{C} \text {, spiral state }(3 \mathrm{~s}) . \\
\text { Curly recovery under alkaline and acidic conditions }\end{array}$ & $\begin{array}{l}\text { Soft robotics with programmable } \\
\text { combination }\end{array}$ & Jing et al. (2019) \\
\hline & $\begin{array}{l}\text { PNIPAAm, PNCS } \\
\text { and PLA }\end{array}$ & $\begin{array}{l}20^{\circ} \mathrm{C} \text { and } 40^{\circ} \mathrm{C}, \mathrm{PH} 3 \text { and } \mathrm{PH} 8 \text {, shrink/expansion } \\
\text { response }\end{array}$ & Artificial muscle & Štular et al. (2019) \\
\hline & CNT and PDMS & $\begin{array}{l}225^{\circ} \mathrm{C} \text {, bending curvature of } 0.3 \mathrm{~cm}^{-1} \text {. Potassium } \\
\text { chloride solution, displacement of } 4 \mathrm{~mm}(4 \mathrm{~s})\end{array}$ & $\begin{array}{l}\text { Crawling robot like an inchworm, a gripper } \\
\text { to grasp }\end{array}$ & Ji et al. (2019) \\
\hline & Dns and PAAM & $\begin{array}{l}\mathrm{PH} 11.5 \text { and } \mathrm{PH} 2.0 \text {, bend and return to original state; } \\
50^{\circ} \mathrm{C} \text {, recovery. }\end{array}$ & Soft robots & Gong et al. (2016) \\
\hline \multirow[t]{5}{*}{$\begin{array}{l}\text { Light, heat,and } \\
\text { humidity }\end{array}$} & GO, CNTs and PDMS & $\begin{array}{l}0.5 \mathrm{w} / \mathrm{cm}^{2} \text { light, bending angle of } 90^{\circ}(2.5 \mathrm{~s}) \text {. } \\
80^{\circ} \mathrm{C} \text {, bending angle of } 180^{\circ}(1.7 \mathrm{~s}) . \\
\mathrm{RH} 90 \% \text {, bending angle of } 137^{\circ}(1.4 \mathrm{~s})\end{array}$ & $\begin{array}{l}\text { Biomimetic devices, humidity control } \\
\text { switches, and optical control medical } \\
\text { devices }\end{array}$ & $\begin{array}{l}\text { Wang et al. } \\
\text { (2018d) }\end{array}$ \\
\hline & GO & $\begin{array}{l}\text { IR light and } 100^{\circ} \mathrm{C} \text {, bending angle of } 90^{\circ}(1 \mathrm{~s}) \text {. } \\
\mathrm{RH} 85 \% \text {, bending angle of } 70^{\circ}(1 \mathrm{~s}) .\end{array}$ & $\begin{array}{l}\text { Multifunctional smart walkers with self- } \\
\text { deformation sensing ability }\end{array}$ & Cheng et al. (2016) \\
\hline & $\begin{array}{l}\text { Nano-size graphite, } \\
\text { PVDF and GO }\end{array}$ & $\begin{array}{l}206 \mathrm{~mW} / \mathrm{cm}^{2} \text { light and } 70^{\circ} \mathrm{C} \text {, bending angle of } 160^{\circ}(4 \mathrm{~s}) \text {. } \\
\mathrm{RH} 23 \% \text { to } 97 \% \text {, bending angle of } 200^{\circ}(13 \mathrm{~s}) .\end{array}$ & $\begin{array}{l}\text { Multi-responsive Bimorph actuators, smart } \\
\text { claw }\end{array}$ & $\begin{array}{l}\text { Zhang et al. } \\
\text { (2020c) }\end{array}$ \\
\hline & GO and BOPP & $\begin{array}{l}80^{\circ} \mathrm{C}, 300 \mathrm{~mW} / \mathrm{cm}^{2} \text { light, bending curvature of } 2.8 \mathrm{~cm}^{-1} \text {. } \\
\mathrm{RH} 20 \% \text { to } 90 \% \text {, bending curvature of } 3.1 \mathrm{~cm}^{-1} \text {. }\end{array}$ & Artificial muscles, bioinspired robotics & Chen et al. (2017) \\
\hline & PG and graphite & $\begin{array}{l}\mathrm{RH} 70 \% \text {, curvature change speed of } 1 \mathrm{~cm}^{-1} \mathrm{~s}^{-1} \text {. } \\
1.2 \mathrm{~W} / \mathrm{cm}^{-2} \text {, curvature change speed of } 1 \mathrm{~cm}^{-1} \mathrm{~s}^{-1} \text {. }\end{array}$ & Soft robotics and smart mechanical devices & Ji et al. (2020) \\
\hline
\end{tabular}

sensitivity to PAA hydrogel (Shang and Theato, 2018a), the bilayer hydrogels show a reversible and repeatable directioncontrollable curving behavior upon variation of temperature $\left(2-50^{\circ} \mathrm{C}\right)$ and $\mathrm{pH}(2$ and 11$)$. At the same time, by combining the inhomogeneity of lateral hydrogel composition (PAA and PNIPAM/PAA) and dimensions (size of PAA and PNIPAM/ PAA region), a complex $3 \mathrm{D}$ deformation also could be generated.
By replacing PAA with 2-carboxyethyl acrylate, the actuator can also respond to ethanol vapor at a slower response speed (Odent et al., 2019). Subsequently, in order to further narrow the temperature difference range of the actuator response, $\mathrm{Li}$ et al. prepared an semi-interpenetrating network hydrogel-based bilayer actuators by generating a PNIPAM-based hydrogel in the presence of positively charged polyelectrolyte pDADMAC on 
a layer of gold-coated PDMS, which showed quickly bidirectional bending behavior in response to solution temperature $\left(25-45^{\circ} \mathrm{C}\right)$ and $\mathrm{PH}(3$ and 6.5) (Li et al., 2017b). To address the weak mechanical properties of hydrogel actuators, heat-chemical response hydrogel actuators composed of SMA, $\mathrm{AA}$, and $\mathrm{QCH}$ utilize the electrostatic interaction between AA and QCH, and hydrophobic interaction of alkyl chains in SMA to provide a high strain stress $(906 \%, 1.64 \mathrm{MPa})$ and fatigue resistance (Jing et al., 2019). Soon afterwards, based on electrostatic spinning technique, a smart actuator with high mechanical properties was obtained by combining submicron particles of PNIPAM and chitosan into a structure of PLA microfibers, which also showed temperature and $\mathrm{pH}$ responsiveness (Štular et al., 2019). Therefore, these actuators have flexible design and is widely used in the field of flexible actuators, even in the field of bionic robots.

\section{Smart Actuator Based on Multiple Light, Heat, and Humidity Stimuli Response}

GO with oxygen-rich groups is the ideal material for multistimuli response actuators. GO-CNT/PDMS double layer film actuator was prepared by embedding a PDMS layer with CNT strips (Wang et al., 2018d). Under light stimulation, the response time of this actuator was longer than that of a GO film actuator prepared by GO suspension casting (Cheng et al., 2016), which has a better humidity bending drive response of $137^{\circ}$. Recently, Zhang et al. further adopted nanoscale graphite, by combining a composite layer of Nano-G and PVDF with GO to achieve bidirectional drive under humidity and light stimulations, further manufacturing a bidirectional walking robot, which the average moving speeds are $0.4 \mathrm{~mm} / \mathrm{s}$ and $1 \mathrm{~mm} / \mathrm{s}$ for moisture and light actuation, respectively. (Zhang Y.-L. et al., 2020). Chen et al. also proposed an actuator based on GO and biaxially oriented polypropylene composites that utilized the wet expansion and photothermal conversion properties of GO, allowing the actuator to achieve a bending curvature of up to $3.1 \mathrm{~cm}^{-1}$ under humidity stimulation, which is higher than that under light stimulation (Chen et al., 2017). In addition, actuators prepared by coating a highly hygroscopic film (pyrolytic graphite) on an antimagnetic graphite film, which can also realize highspeed linear motion $(88 \mathrm{~mm} / \mathrm{s})$ and turning motion $\left(180^{\circ} / \mathrm{s}\right)$ under the IR light and humidity (Ji et al., 2020). Above all, the excellent electrical, mechanical, and thermal properties of graphene enable it to be widely used in materials and structural components of multiple smart actuators.

The main research progress of smart actuators based on multiple stimuli responses are summarized in Table 2.

\section{CONCLUSION}

In summary, the design concept of stimulus-response smart actuators mainly comes from organisms in nature, which is to prepare actuators with similar stimulus responses by observing behavioral characteristics of life forms. Most of current ongoing research involves the biocompatible actuators that can operate under multiple stimuli conditions. Among them, GO, CNTs, and other materials with high thermal expansion properties (such as Dns and p-phenylenediamine) are used as functional dielectric materials. Elastomeric polymer materials with good biocompatibility, such as common PDMS, PVDF, and PNIPAM, are commonly used as the basic flexible materials that can respond to light, heat, electricity and chemical stimuli. However, most of the these actuators are double-layered structures and face the problems of instability and easy separation between boundary layers. In recent years, fiber-based actuators with a spiral structure have received widespread attention because of their mechanical strength and multi-response editability. But they have only been applied in the fields of light, heat, and humidity stimulus response. Correspondingly, chemical stimulus response smart actuators have unique functional changes that are not yet applicable to other stimulus response actuators, their slow response time limits their application. Despite these limitations, it is expected that the stability and responsiveness of smart actuators will continue to increase, enabled by the discovery of responsive materials with high photothermal conversion efficiency and multi-functionality. Moreover, porous fiber microstructures and various spun fiber structures can be used to enhance the transport of swollen or contracted water molecules and increase the response speed. Thus, it is expected that there will be broad application prospects and high added value in the fields of smart robots, artificial muscles, biological sensing, and smart medical equipment in the future.

\section{AUTHOR CONTRIBUTIONS}

QZ: Literature related to different stimulus response smart actuators is collected, categorized, and organized, the mechanistic map of the review is drawn, and the abstract, single stimulus response smart actuator content, and conclusions are written. CX: Summary background, multiple stimulus response smart actuator content is written, and response summary table is drawn. This author contributed equally to this work and should be considered co-first authors. ZJ: Ideas to summarize the integrity of the content are provided and help build the overall writing structure, the final revision of the review was completed. FF: The core concepts of the review were provided and the mid-term content was sorted out, part of the review framework was provided, and the final revision of the review was completed. MZ: The review language application and format was corrected and modified. CC: Correction and modification in the content of the review writing process. All authors approved it for publication.

\section{FUNDING}

This work was financially supported by the National Key Research Project of China (2016YFB0302700), Young Science and Technology Talent Sailing Project of Shanghai (19YF1417800). 


\section{REFERENCES}

An, Y., Gao, L., and Wang, T. (2020). Graphene Oxide/Alginate Hydrogel Fibers with Hierarchically Arranged Helical Structures for Soft Actuator Application. ACS Appl. Nano Mater. 3 (6), 5079-5087. doi:10.1021/acsanm.0c00351

Chen, L., Weng, M., Zhou, P., Zhang, L., Huang, Z., and Zhang, W. (2017). Multiresponsive Actuators Based on a Graphene Oxide Composite: Intelligent Robot and Bioinspired Applications. Nanoscale 9 (28), 9825-9833. doi:10.1039/ c7nr01913k

Cheng, H., Zhao, F., Xue, J., Shi, G., Jiang, L., and Qu, L. (2016). One Single Graphene Oxide Film for Responsive Actuation. ACS Nano 10 (10), 9529-9535. doi:10.1021/acsnano.6b04769

Cheng, Z., Ma, S., Zhang, Y., Huang, S., Chen, Y., and Yu, H. (2017). Photomechanical Motion of Liquid-Crystalline Fibers Bending Away from a Light Source. Macromolecules 50 (21), 8317-8324. doi:10.1021/acs.macromol. $7 \mathrm{~b} 01741$

Chortos, A., Hajiesmaili, E., Morales, J., Clarke, D. R., and Lewis, J. A. (2019). 3D Printing of Interdigitated Dielectric Elastomer Actuators. Adv. Funct. Mater. 30 (1), 1907375. doi:10.1002/adfm.201907375

Dai, L., Ma, M., Xu, J., Si, C., Wang, X., Liu, Z., et al. (2020). All-Lignin-Based Hydrogel with Fast pH-Stimuli Responsiveness for Mechanical Switching and Actuation. Chem. Mater. 32 (10), 4324-4330. doi:10.1021/acs.chemmater. 0c01198

Deng, J., Li, J., Chen, P., Fang, X., Sun, X., Jiang, Y., et al. (2016). Tunable Photothermal Actuators Based on a Pre-programmed Aligned Nanostructure. J. Am. Chem. Soc. 138, 225-230. doi:10.1021/jacs.5b10131

Deng, J., Li, J., Chen, P., Fang, X., Sun, X., Jiang, Y., et al. (2015). Tunable Photothermal Actuators Based on a Pre-programmed Aligned Nanostructure. J. Am. Chem. Soc. 138 (1), 225-230. doi:10.1021/jacs.5b10131

Diller, E., Zhuang, J., Zhan Lum, G., Edwards, M. R., and Sitti, M. (2014). Continuously Distributed Magnetization Profile for Millimeter-Scale Elastomeric Undulatory Swimming. Appl. Phys. Lett. 104 (17), 174101. doi:10.1063/1.4874306

Finkelmann, H., Nishikawa, E., Pereira, G. G., and Warner, M. (2001). A New Opto-Mechanical Effect in Solids. Phys. Rev. Lett. 87 (1). doi:10.1103/ PhysRevLett.87.015501

Foroughi, J., Spinks, G. M., Wallace, G. G., Oh, J., Kozlov, M. E., Fang, S., et al. (2011). Torsional Carbon Nanotube Artificial Muscles. Science 334 (6055), 494-497. doi:10.1126/science.1211220

Gao, P., Li, J., and Shi, Q. (2019). A Hollow Polyethylene Fiber-Based Artificial Muscle. Adv. Fiber Mater. 1 (3-4), 214-221. doi:10.1007/s42765-019-00019-6

Garstecki, P., Tierno, P., Weibel, D. B., Sagués, F., and Whitesides, G. M. (2009). Propulsion of Flexible Polymer Structures in a Rotating Magnetic Field. J. Phys. Condens. Matter 21 (20), 204110. doi:10.1088/0953-8984/21/20/204110

Gelebart, A. H., Vantomme, G., Meijer, E. W., and Broer, D. J. (2017). Mastering the Photothermal Effect in Liquid Crystal Networks: A General Approach for Self-Sustained Mechanical Oscillators. Adv. Mater. 29 (18), 1606712. doi:10. 1002/adma.201606712

Gestos, A., Whitten, P. G., Wallace, G. G., and Spinks, G. M. (2012). Actuating Individual Electrospun Hydrogel Nanofibres. Soft Matter 8 (31), 8082-8087. doi:10.1039/c2sm25387a

Gong, X.-L., Xiao, Y.-Y., Pan, M., Kang, Y., Li, B.-J., and Zhang, S. (2016).pH- and Thermal-Responsive Multishape Memory Hydrogel. ACS Appl. Mater. Inter. 8 (41), 27432-27437. doi:10.1021/acsami.6b09605

Grinthal, A., and Aizenberg, J. (2013). Adaptive All the Way Down: Building Responsive Materials from Hierarchies of Chemomechanical Feedback. Chem. Soc. Rev. 42 (17), 7072. doi:10.1039/c3cs60045a

Han, B., Gao, Y.-Y., Zhang, Y.-L., Liu, Y.-Q., Ma, Z.-C., Guo, Q., et al. (2020). Multi-field-coupling Energy Conversion for Flexible Manipulation of Graphene-Based Soft Robots. Nano Energy 71, 104578. doi:10.1016/j.nanoen. 2020.104578

Hasan, T. (2020). Mechanical Properties of Nanomaterials: A Review. Nanotechnology Rev. 9 (1), 259-273. doi:10.1515/ntrev-2020-0021

He, F., You, X., Gong, H., Yang, Y., Bai, T., Wang, W., et al. (2020). Stretchable, Biocompatible, and Multifunctional Silk Fibroin-Based Hydrogels toward Wearable Strain/Pressure Sensors and Triboelectric Nanogenerators. ACS Appl. Mater. Inter. 12, 6442-6450. doi:10.1021/acsami.9b19721
He, X., Sun, Y., Wu, J., Wang, Y., Chen, F., Fan, P., et al. (2019). Dual-stimulus Bilayer Hydrogel Actuators with Rapid, Reversible, Bidirectional Bending Behaviors. J. Mater. Chem. C 7 (17), 4970-4980. doi:10.1039/c9tc00180h

Heuchel, M., Razzaq, M. Y., Kratz, K., Behl, M., and Lendlein, A. (2015). Modeling the Heat Transfer in Magneto-Sensitive Shape-Memory Polymer Nanocomposites with Dynamically Changing Surface Area to Volume Ratios. Polymer 65, 215-222. doi:10.1016/j.polymer.2015.03.063

Hore, D., Majumder, A., Mondal, S., Roy, A., and Ghatak, A. (2012). How to Make a cylinder Roll Uphill. Soft Matter 8 (18), 5038-5042. doi:10.1039/c2sm07282c

Hu, W., Lum, G. Z., Mastrangeli, M., and Sitti, M. (2018). Small-scale Soft-Bodied Robot with Multimodal Locomotion. Nature 554 (7690), 81-85. doi:10.1038/ nature25443

Hua, D., Zhang, X., Ji, Z., Yan, C., Yu, B., Li, Y., et al. (2018). 3D Printing of Shape Changing Composites for Constructing Flexible Paper-Based Photothermal Bilayer Actuators. J. Mater. Chem. C 6 (8), 2123-2131. doi:10.1039/c7tc05710e

Huang, L., Jiang, R., Wu, J., Song, J., Bai, H., Li, B., et al. (2017). Ultrafast Digital Printing toward 4D Shape Changing Materials. Adv. Mater. 29 (7), 1605390. doi:10.1002/adma.201605390

Huang, L., Xie, X., Huang, H., Zhu, J., Yu, J., Wang, Y., et al. (2020). Electrospun Polyamide-6 Nanofiber for Hierarchically Structured and Multi-Responsive Actuator. Sensors Actuators A: Phys. 302, 111793. doi:10.1016/j.sna.2019. 111793

Huang, Y., Liang, J., and Chen, Y. (2012). The Application of Graphene Based Materials for Actuators. J. Mater. Chem. 22 (9), 3671. doi:10.1039/c2jm15536b

Hubbard, A. M., Cui, W., Huang, Y., Takahashi, R., Dickey, M. D., Genzer, J., et al. (2019). Hydrogel/Elastomer Laminates Bonded via Fabric Interphases for Stimuli-Responsive Actuators. Matter 1 (3), 674-689. doi:10.1016/j.matt. 2019.04.008

Hyeon, J. S., Park, J. W., Baughman, R. H., and Kim, S. J. (2019). Electrochemical Graphene/carbon Nanotube Yarn Artificial Muscles. Sensors Actuators B: Chem. 286, 237-242. doi:10.1016/j.snb.2019.01.140

Ji, H. K., Pyo, J., and Kim, T. (2020). Highly Mobile Levitating Soft Actuator Driven by Multistimuli-Responses. Adv. Mater. Inter. 7.

Ji, Y., Xing, Y., Li, X., and Shao, L.-H. (2019). Dual-Stimuli Responsive Carbon Nanotube Sponge-PDMS Amphibious Actuator. Nanomaterials 9 (12), 1704. doi:10.3390/nano9121704

Jia, H., Mailand, E., Zhou, J., Huang, Z., Dietler, G., Kolinski, J. M., et al. (2019a). Universal Soft Robotic Microgripper. Small 15 (4), 1803870. doi:10.1002/smll. 201803870

Jia, T., Wang, Y., Dou, Y., Li, Y., Jung de Andrade, M., Wang, R., et al. (2019b). Moisture Sensitive Smart Yarns and Textiles from Self-Balanced Silk Fiber Muscles. Adv. Funct. Mater. 29 (18), 1808241. doi:10.1002/adfm. 201808241

Jiang, H. Y., Kelch, S., and Lendlein, A. (2006). Polymers Move in Response to Light. Adv. Mater. 18 (11), 1471-1475. doi:10.1002/adma.200502266

Jiang, S., Liu, F., Lerch, A., Ionov, L., and Agarwal, S. (2015). Unusual and Superfast Temperature-Triggered Actuators. Adv. Mater. 27 (33), 4865-4870. doi:10. 1002/adma.201502133

Jing, H., He, L., Feng, J., Fu, H., Guan, S., and Guo, P. (2019). High Strength Hydrogels with Multiple Shape-Memory Ability Based on Hydrophobic and Electrostatic Interactions. Soft Matter 15 (26), 5264-5270. doi:10.1039/ c9sm00869a

Kim, D., Lee, H. S., and Yoon, J. (2016). Highly Bendable Bilayer-type PhotoActuators Comprising of Reduced Graphene Oxide Dispersed in Hydrogels. Sci. Rep. 6 (1). doi:10.1038/srep20921

Lee, J. A., Li, N., Haines, C. S., Kim, K. J., Lepró, X., Ovalle-Robles, R., et al. (2017). Electrochemically Powered, Energy-Conserving Carbon Nanotube Artificial Muscles. Adv. Mater. 29 (31), 1700870. doi:10.1002/adma. 201700870

Leeladhar, Raturi, P., and Singh, J. P. (2018). Sunlight-driven Eco-Friendly Smart Curtain Based on Infrared Responsive Graphene Oxide-Polymer Photoactuators. Sci. Rep. 8 (1). doi:10.1038/s41598-018-21871-3

Lei, Z., Zhu, W., Sun, S., and Wu, P. (2016). MoS2-based Dual-Responsive Flexible Anisotropic Actuators. Nanoscale 8 (44), 18800-18807. doi:10.1039/ c6nr07265h

Leng, J., Lan, X., Liu, Y., and Du, S. (2011). Shape-memory Polymers and Their Composites: Stimulus Methods and Applications. Prog. Mater. Sci. 56 (7), 1077-1135. doi:10.1016/j.pmatsci.2011.03.001 
Li, J., Zhang, R., Mou, L., Jung de Andrade, M., Hu, X., Yu, K., et al. (2019a). Photothermal Bimorph Actuators with In-Built Cooler for Light Mills, Frequency Switches, and Soft Robots. Adv. Funct. Mater., 1808995. doi:10. 1002/adfm.201808995

Li, L., Meng, J., Hou, C., Zhang, Q., Li, Y., Yu, H., et al. (2018). Dual-Mechanism and Multimotion Soft Actuators Based on Commercial Plastic Film. ACS Appl. Mater. Inter. 10 (17), 15122-15128. doi:10.1021/acsami.8b00396

Li, M.-H., Keller, P., Li, B., Wang, X., and Brunet, M. (2003). Light-Driven Side-On Nematic Elastomer Actuators. Adv. Mater. 15 (78), 569-572. doi:10.1002/adma. 200304552

Li, M., Wang, X., Dong, B., and Sitti, M. (2020a). In-air Fast Response and High Speed Jumping and Rolling of a Light-Driven Hydrogel Actuator. Nat. Commun. 11, 3988. doi:10.1038/s41467-020-17775-4

Li, S., Tu, Y., Bai, H., Hibi, Y., Wiesner, L. W., Pan, W., et al. (2019b). Simple Synthesis of Elastomeric Photomechanical Switches that Self-Heal. Macromol. Rapid Commun. 40 (4), 1800815. doi:10.1002/marc.201800815

Li, X., Cai, X., Gao, Y., and Serpe, M. J. (2017a). Reversible Bidirectional Bending of Hydrogel-Based Bilayer Actuators. J. Mater. Chem. B 5 (15), 2804-2812. doi:10. $1039 / \mathrm{c} 7 \mathrm{tb} 00426 \mathrm{e}$

Li, X., Cai, X., Gao, Y., and Serpe, M. J. (2017b). Reversible Bidirectional Bending of Hydrogel-Based Bilayer Actuators. J. Mater. Chem. B 5. doi:10.1039/c7tb00426e

Li, Z., Liu, P., Ji, X., Gong, J., Hu, Y., Wu, W., et al. (2020b). Bioinspired Simultaneous Changes in Fluorescence Color, Brightness, and Shape of Hydrogels Enabled by AIEgens. Adv. Mater. 32 (11), 1906493. doi:10.1002/ adma.201906493

Lin, S., Wang, Z., Chen, X., Ren, J., and Ling, S. (2020). Ultrastrong and Highly Sensitive Fiber Microactuators Constructed by Force-Reeled Silks. Adv. Sci. 7 (6), 1902743. doi:10.1002/advs.201902743

Lindsey, H., Kirstin, P., Guo, Z., and Sitti, M. (2017). Soft Actuators for Small-Scale Robotics. Adv. Mater. 29. 1603483. doi:10.1002/adma.201603483

Lu, C., Yang, Y., Wang, J., Fu, R., Zhao, X., Zhao, L., et al. (2018a). Highperformance Graphdiyne-Based Electrochemical Actuators. Nat. Commun. 9 (1). doi:10.1038/s41467-018-03095-1

Lu, H., Zhang, M., Yang, Y., Huang, Q., Fukuda, T., Wang, Z., et al. (2018b). A Bioinspired Multilegged Soft Millirobot that Functions in Both Dry and Wet Conditions. Nat. Commun. 9 (1). doi:10.1038/s41467-018-06491-9

Meng, J., Hou, C., Zhang, Q., Li, Y., and Wang, H. (2019). Light-driven Artificial Muscles Based on Electrospun Microfiber Yarns. Sci. China Technol. Sci. 62 (6), 965-970. doi:10.1007/s11431-018-9413-4

Mo, K., He, M., Cao, X., and Chang, C. (2020). Direct Current Electric Field Induced Gradient Hydrogel Actuators with Rapid Thermo-Responsive Performance as Soft Manipulators. J. Mater. Chem. C 8 (8), 2756-2763. doi:10.1039/c9tc06407a

Morales, D., Palleau, E., Dickey, M. D., and Velev, O. D. (2014). Electro-actuated Hydrogel Walkers with Dual Responsive Legs. Soft Matter 10 (9), 1337-1348. doi:10.1039/c3sm51921j

Mu, J., Wang, G., Yan, H., Li, H., Wang, X., Gao, E., et al. (2018). Molecularchannel Driven Actuator with Considerations for Multiple Configurations and Color Switching. Nat. Commun. 9 (1). doi:10.1038/s41467-018-03032-2

Must, I., Kaasik, F., Pldsalu, I., Mihkels, L., Johanson, U., Punning, A., et al. (2015). Ionic and Capacitive Artificial Muscle for Biomimetic Soft Robotics. Adv. Eng. Mater. 17 (1). doi:10.1002/adem.201400246

Nguyen, V. H., Tabassian, R., Oh, S., Nam, S., and Oh, I. K. (2020). StimuliResponsive MXene-Based Actuators. Adv. Funct. Mater. 30, 1909504. doi:10. 1002/adfm.201909504

Nhat, N. L. Q., and Truong Thinh, N. (2015). Development of the Bending Actuator with Nafion-Pt IPMC Tube. Adv. Mater. Res. 1119. doi:10.4028/www. scientific.net/amr.1119.251

Odent, J., Vanderstappen, S., Toncheva, A., Pichon, E., Wallin, T. J., Wang, K., et al. (2019). Hierarchical Chemomechanical Encoding of Multi-Responsive Hydrogel Actuators via 3D Printing. J. Mater. Chem. A. 7 (25), 15395-15403. doi:10.1039/c9ta03547h

Pilz da Cunha, M., Ambergen, S., Debije, M. G., Homburg, E. F. G. A., den Toonder, J. M. J., and Schenning, A. P. H. J. (2020). A Soft Transporter Robot Fueled by Light. Adv. Sci. 7 (5), 1902842. doi:10.1002/advs. 201902842

Pilz da Cunha, M., Foelen, Y., Raak, R. J. H., Murphy, J. N., Engels, T. A. P., Debije, M. G., et al. (2019). An Untethered Magnetic- and Light-Responsive Rotary
Gripper: Shedding Light on Photoresponsive Liquid Crystal Actuators. Adv. Opt. Mater. 7 (7), 1801643. doi:10.1002/adom.201801643

Power, M., Thompson, A. J., Anastasova, S., and Yang, G.-Z. (2018). A Monolithic Force-Sensitive 3D Microgripper Fabricated on the Tip of an Optical Fiber Using 2-Photon Polymerization. Small 14 (16), 1703964. doi:10.1002/smll. 201703964

Santhiago, M., Bettini, J., Araújo, S. R., and Bufon, C. C. B. (2016). ThreeDimensional Organic Conductive Networks Embedded in Paper for Flexible and Foldable Devices. ACS Appl. Mater. Inter. 8 (17), 10661-10664. doi:10. 1021/acsami.6b02589

Seo, D. K., Kang, T. J., Kim, D. W., and Kim, Y. H. (2012). Twistable and Bendable Actuator: a CNT/polymer sandwich Structure Driven by thermal Gradient. Nanotechnology 23 (7), 075501. doi:10.1088/0957-4484/23/7/075501

Shang, J., and Theato, P. (2018a). Smart Composite Hydrogel with pH-, Ionic Strength- and Temperature-Induced Actuation. Soft Matter 14. doi:10.1039/ c8sm01728j

Shang, J., and Theato, P. (2018b). Smart Composite Hydrogel with pH-, Ionic Strength- and Temperature-Induced Actuation. Soft Matter 14 (41) 8401-8407. doi:10.1039/c8sm01728j

Shi, K., Liu, Z., Wei, Y.-Y., Wang, W., Ju, X.-J., Xie, R., et al. (2015). Near-Infrared Light-Responsive Poly(N-isopropylacrylamide)/Graphene Oxide Nanocomposite Hydrogels with Ultrahigh Tensibility. ACS Appl. Mater. Inter. 7 (49), 27289-27298. doi:10.1021/acsami.5b08609

Shin, B., Ha, J., Lee, M., Park, K., Park, G. H., Choi, T. H., et al. (2018). Hygrobot- A Self-Locomotive Ratcheted Actuator Powered by Environmental Humidity. ScienceE Robotics 3, 8. doi:10.1126/scirobotics.aar2629

Song, M., Xiao, M., Zhang, L., Zhang, D., Liu, Y., Wang, F., et al. (2016). Generating Induced Current through the Diving-Surfacing Motion of a StimulusResponsive Smart Device. Nano Energy 20, 233-243. doi:10.1016/j.nanoen. 2015.11.037

Stroganov, V., Zakharchenko, S., Sperling, E., Meyer, A. K., Schmidt, O. G., and Ionov, L. (2014). Biodegradable Self-Folding Polymer Films with Controlled Thermo-Triggered Folding. Adv. Funct. Mater. 24 (27), 4357-4363. doi:10. 1002/adfm.201400176

Štular, D., Kruse, M., Župunski, V., Kreinest, L., Medved, J., Gries, T., et al. (2019). Smart Stimuli-Responsive Polylactic Acid-Hydrogel Fibers Produced via Electrospinning. Fibers Polym. 20 (9), 1857-1868. doi:10.1007/s12221-0199157-8

Sturm, S., Siglreitmeier, M., Wolf, D., Vogel, K., Gratz, M., Faivre, D., et al. (2019). Magnetic Nanoparticle Chains in Gelatin Ferrogels: Bioinspiration from Magnetotactic Bacteria. Adv. Funct. Mater. 29 (45), 1905996. doi:10.1002/ adfm.201905996

Takemura, K., Yajima, F., Yokota, S., and Kazuya, E. (2008). Integration of Micro Artificial Muscle Cells Using Electro-Conjugate Fluid. Sensors Actuators A Phys. 144 (2), 348-353. doi:10.1016/j.sna.2008.02.011

Verpaalen, R. C. P., Pilz da Cunha, M., Engels, T. A. P., Debije, M. G., and Schenning, A. P. H. J. (2020). Liquid Crystal Networks on Thermoplastics: Reprogrammable Photo-Responsive Actuators. Angew. Chem. Int. Ed. 59 (11), 4532-4536. doi:10.1002/anie.201915147

Wang, E., Desai, M. S., and Lee, S.-W. (2013). Light-Controlled Graphene-Elastin Composite Hydrogel Actuators. Nano Lett. 13 (6), 2826-2830. doi:10.1021/ nl401088b

Wang, G., Xia, H., Sun, X.-C., Lv, C., Li, S.-X., Han, B., et al. (2018a). Actuator and Generator Based on Moisture-Responsive PEDOT: PSS/PVDF Composite Film. Sensors Actuators B: Chem. 255, 1415-1421. doi:10.1016/j.snb.2017. 08.125

Wang, J., Liu, Y., Cheng, Z., Xie, Z., and Fan, Z. (2020a). Highly Conductive MXene Film Actuator Based on Moisture Gradients. Angew. Chem.

Wang, T., Li, M., Zhang, H., Sun, Y., and Dong, B. (2018b). A Multi-Responsive Bidirectional Bending Actuator Based on Polypyrrole and agar Nanocomposites. J. Mater. Chem. C 6 (24), 6416-6422. doi:10.1039/ c8tc00747k

Wang, W., Xiang, C., Liu, Q., Li, M., Zhong, W., Yan, K., et al. (2018c). Natural Alginate Fiber-Based Actuator Driven by Water or Moisture for Energy Harvesting and Smart Controller Applications. J. Mater. Chem. A. 6 (45), 22599-22608. doi:10.1039/c8ta08064j

Wang, W., Xiang, C., Sun, D., Li, M., Yan, K., and Wang, D. (2019a). Photothermal and Moisture Actuator Made with Graphene Oxide and Sodium Alginate for 
Remotely Controllable and Programmable Intelligent Devices. ACS Appl. Mater. Inter. 11 (24), 21926-21934. doi:10.1021/acsami.9b05136

Wang, W., Xiang, C., Zhu, Q., Zhong, W., Li, M., Yan, K., et al. (2018d). Multistimulus Responsive Actuator with GO and Carbon Nanotube/PDMS Bilayer Structure for Flexible and Smart Devices. ACS Appl. Mater. Inter. 10 (32), 27215-27223. doi:10.1021/acsami.8b08554

Wang, X., Zhang, Q., Liu, P., Zhu, X., and Huang, Y. (2020b). An Ultrafast Response and Precisely Controllable Soft Electromagnet Actuator Based on Ecoflex Rubber Film Filled with Neodymium-Iron-boron. J. Micromechanics Microengineering.

Wang, Y., Cui, H., Zhao, Q., and Du, X. (2019b). Chameleon-Inspired StructuralColor Actuators. Matter 1 (3), 626-638. doi:10.1016/j.matt.2019.05.012

Wang, Y., Guo, Q., Su, G., Cao, J., Liu, J., and Zhang, X. (2019c). Hierarchically Structured Self-Healing Actuators with Superfast Light- and MagneticResponse. Adv. Funct. Mater. 29 (50), 1906198. doi:10.1002/adfm.201906198

Wei, Y., Li, S., Zhang, X., Fu, Y., and Chen, K. (2020). Smart Devices Based on the Soft Actuator with Nafion-Polypropylene-PDMS/Graphite Multilayer Structure. Appl. Sci. 10 (5), 1829. doi:10.3390/app10051829

Weng, M., Duan, Y., Zhou, P., Huang, F., Zhang, W., and Chen, L. (2020). Electricfish-inspired Actuator with Integrated Energy-Storage Function. Nano Energy 68, 104365. doi:10.1016/j.nanoen.2019.104365

Weng, M., Zhou, P., Chen, L., Zhang, L., Zhang, W., Huang, Z., et al. (2016). Multiresponsive Bidirectional Bending Actuators Fabricated by a Pencil-OnPaper Method. Adv. Funct. Mater. 26 (40), 7244-7253. doi:10.1002/adfm.201602772

Winchester, D. J. (2009). The Number of Positive Nodes and the Ratio of Positive to Excised Nodes Are Significant Predictors of Survival in Women with Micrometastatic Node-Positive Breast Cancer. Breast Dis. A Year Book Q. 20 (1), 69-70. doi:10.1016/s1043-321x(09)79225-2

Xiao, P., Yi, N., Zhang, T., Huang, Y., Chang, H., Yang, Y., et al. (2016). Construction of a Fish-like Robot Based on High Performance Graphene/PVDF Bimorph Actuation Materials. Adv. Sci. 3 (6), 1500438. doi:10.1002/advs.201500438

Xu, J., Wang, G., Wu, Y., Ren, X., and Gao, G. (2019). Ultrastretchable Wearable Strain and Pressure Sensors Based on Adhesive, Tough, and Self-Healing Hydrogels for Human Motion Monitoring. ACS Appl. Mater. Inter. 11 (28). doi:10.1021/acsami.9b08369

Xu, Z., Liu, S., Kang, Y., and Wang, M. (2015). Glutathione-Responsive Polymeric Micelles Formed by a Biodegradable Amphiphilic Triblock Copolymer for Anticancer Drug Delivery and Controlled Release. ACS Biomater. Sci. Eng. 1 (7), 585-592. doi:10.1021/acsbiomaterials.5b00119

Yamamoto, Y., Kanao, K., Arie, T., Akita, S., and Takei, K. (2015). Air AmbientOperated pNIPAM-Based Flexible Actuators Stimulated by Human Body Temperature and Sunlight. ACS Appl. Mater. Inter. 7 (20), 11002-11006. doi:10.1021/acsami.5b02544

Yang, Y., Pei, Z., Li, Z., Wei, Y., and Ji, Y. (2016). Making and Remaking Dynamic 3D Structures by Shining Light on Flat Liquid Crystalline Vitrimer Films without a Mold. J. Am. Chem. Soc. 138 (7), 2118-2121. doi:10.1021/jacs.5b12531

Yao, C., Liu, Z., Yang, C., Wang, W., Ju, X.-J., Xie, R., et al. (2015). Poly(N-isopropylacrylamide)-Clay Nanocomposite Hydrogels with Responsive Bending Property as Temperature-Controlled Manipulators. Adv. Funct. Mater. 25 (20), 2980-2991. doi:10.1002/adfm.201500420

Yoshida, K., Nakajima, S., Kawano, R., and Onoe, H. (2018). Spring-shaped Stimuli-Responsive Hydrogel Actuator with Large Deformation. Sensors Actuators B: Chem. 272, 361-368. doi:10.1016/j.snb.2018.05.174

Yu, Y., Nakano, M., and Ikeda, T. (2003). Photomechanics: Directed Bending of a Polymer Film by Light. Nature 425 (425), 145. doi:10.1038/425145a

Yu, Y., and Ikeda, T. (2010). Photodeformable Polymers: A New Kind of Promising Smart Material for Micro- and Nano-Applications. Macromolecular Chem. Phys. 206 (17), 1705-1708.
Zang, J., Ryu, S., Pugno, N., Wang, Q., Tu, Q., Buehler, M. J., et al. (2013). Multifunctionality and Control of the Crumpling and Unfolding of Large-Area Graphene. Nat. Mater 12 (4), 321-325. doi:10.1038/nmat3542

Zeng, H., Zhang, H., Ikkala, O., and Priimagi, A. (2020). Associative Learning by Classical Conditioning in Liquid Crystal Network Actuators. Matter 2 (1), 194-206. doi:10.1016/j.matt.2019.10.019

Zhang, L., Pan, J., Liu, Y., Xu, Y., and Zhang, A. (2020a). NIR-UV Responsive Actuator with Graphene Oxide/Microchannel-Induced Liquid Crystal Bilayer Structure for Biomimetic Devices. ACS Appl. Mater. Inter. 12 (5), 6727-6735. doi:10.1021/acsami.9b20672

Zhang, L., Zhang, X., Li, L., Liu, Y., Wang, D., Xu, L., et al. (2019). Fabrication of Photothermally Responsive Nanocomposite Hydrogel through 3D Printing. Macromol. Mater. Eng. 305 (2), 1900718. doi:10.1002/mame. 201900718

Zhang, X., Xu, X., Chen, L., Zhang, C., and Liao, L. (2020b). Multi-responsive Hydrogel Actuator with Photo-Switchable Color Changing Behaviors. Dyes Pigm. 174, 108042. doi:10.1016/j.dyepig.2019.108042

Zhang, Y.-L., Ma, J.-N., Liu, S., Han, D.-D., Liu, Y.-Q., Chen, Z.-D., et al. (2020c). A "Yin"-"Yang" Complementarity Strategy for Design and Fabrication of DualResponsive Bimorph Actuators. Nano Energy 68, 104302. doi:10.1016/j.nanoen. 2019.104302

Zhang, Y., Jiang, H., Li, F., Xia, Y., Lei, Y., Jin, X., et al. (2017). Graphene Oxide Based Moisture-Responsive Biomimetic Film Actuators with Nacre-like Layered Structures. J. Mater. Chem. A. 5 (28), 14604-14610. doi:10.1039/c7ta04208f

Zhang, Y., Wang, Z., Yang, Y., Chen, Q., Qian, X., Wu, Y., et al. (2020d). Seamless Multimaterial 3D Liquid-Crystalline Elastomer Actuators for NextGeneration Entirely Soft Robots. Sci. Adv. 6 (9), 8606. doi:10.1126/sciadv. aay 8606

Zhao, F., Liang, Y., Cheng, H., Jiang, L., and Qu, L. (2016). Highly Efficient Moisture-Enabled Electricity Generation from Graphene Oxide Frameworks. Energy Environ. Sci. 9 (3), 912-916. doi:10.1039/c5ee03701h

Zhao, Q., Heyda, J., Dzubiella, J., Täuber, K., Dunlop, J. W. C., and Yuan, J. (2015). Sensing Solvents with Ultrasensitive Porous Poly(ionic Liquid) Actuators. Adv. Mater. 27 (18), 2913-2917. doi:10.1002/adma.201500533

Zhao, Y., Xu, Z., Parhizkar, M., Fang, J., Wang, X., and Lin, T. (2012). Magnetic Liquid Marbles, Their Manipulation and Application in Optical Probing. Microfluid Nanofluid 13 (4), 555-564. doi:10.1007/s10404-0120976-9

Zheng, L., Dong, S., Nie, J., Li, S., Ren, Z., Ma, X., et al. (2019). Dual-Stimulus Smart Actuator and Robot Hand Based on a Vapor-Responsive PDMS Film and Triboelectric Nanogenerator. ACS Appl. Mater. Inter. 11 (45), 42504-42511. doi:10.1021/acsami.9b15574

Zheng, S. Y., Shen, Y., Zhu, F., Yin, J., Qian, J., Fu, J., et al. (2018). Programmed Deformations of 3D-Printed Tough Physical Hydrogels with High Response Speed and Large Output Force. Adv. Funct. Mater. 28 (37), 1803366. doi:10. 1002/adfm.201803366

Conflict of Interest: The authors declare that the research was conducted in the absence of any commercial or financial relationships that could be construed as a potential conflict of interest.

Copyright $\odot 2021$ Zheng, Xu, Jiang, Zhu, Chen and Fu. This is an open-access article distributed under the terms of the Creative Commons Attribution License (CC BY). The use, distribution or reproduction in other forums is permitted, provided the original author(s) and the copyright owner(s) are credited and that the original publication in this journal is cited, in accordance with accepted academic practice. No use, distribution or reproduction is permitted which does not comply with these terms. 